\title{
The role of harp seals, fisheries and food availability in driving the dynamics of northern cod
}

\author{
Alejandro D. Buren ${ }^{1,3, *}$, Mariano Koen-Alonso ${ }^{2}$, Garry B. Stenson ${ }^{2}$ \\ ${ }^{1}$ Memorial University of Newfoundland, St. John's, Newfoundland A1B 3X9, Canada \\ ${ }^{2}$ Northwest Atlantic Fisheries Centre, Fisheries and Oceans Canada, PO Box 5667, St. John's, Newfoundland A1C 5X1, Canada \\ ${ }^{3}$ Present address: Northwest Atlantic Fisheries Centre, Fisheries and Oceans Canada, PO Box 5667, St. John's, \\ Newfoundland A1C 5X1, Canada
}

\begin{abstract}
The Atlantic cod Gadus morhua population off Newfoundland collapsed in the early 1990s due to over-exploitation, and despite marked reduction in fishing effort the stock remains depressed. Harp seal Pagophilus groenlandicus predation has been repeatedly proposed as an explanation for this lack of recovery, but other hypotheses include reduced prey availability and/or food quality (i.e. lack of capelin Mallotus villosus), as well as fisheries catches and environmental effects. Using a bioenergetics-allometric model, we gauged the relative contributions of these drivers on the lack of recovery and dynamics of the northern cod stock. Biomass dynamics were best explained by a combination of fisheries removals and capelin availability, whereas seal consumption was found not to be an important driver of the northern cod stock. Prey availability was linked to reduced somatic condition during the 1990s and 2000s. We discuss evidence that suggests that cod may be experiencing depensatory dynamics, but not related to a 'predator pit effect'. Our study suggests that trophic control is bottom-up, and that a depressed capelin stock could be a serious impediment for cod rebuilding.
\end{abstract}

KEY WORDS: Impact · Predation · Predator-prey · Marine mammal · Groundfish · Forage fish · Predator pit

Resale or republication not permitted without written consent of the publisher

\section{INTRODUCTION}

The Atlantic cod Gadus morhua stocks off eastern Canada once sustained one of the world's largest fisheries, and supported the livelihoods of many generations. During the late 1980s and first half of the 1990s, 6 populations of Atlantic cod throughout Atlantic Canada collapsed. These stock collapses and subsequent failures to recover, and the concomitant increases in the abundance of grey Halichoerus grypus and harp seals Phoca groenlandica off the coasts of eastern Canada (Hammill \& Stenson 2011, Thomas et al. 2011, Hammill et al. 2013) prompted enquiries to assess whether these events were related (Bundy 2001, McLaren et al. 2001, DFO 2003a,b, 2008a, 2009, 2011a, Trzcinski et al. 2006, 2009, Chassot et al. 2009, Benoît et al. 2011, Swain et al. 2011). Trophic interactions between marine mammals and fisheries, particularly the potential detrimental effects that top predators may have on fish stocks, have been considered for decades (e.g. May et al. 1979, Flaaten 1988, Yodzis 1994, Punt \& Butterworth 1995, Northridge 1991 and references therein, Harwood 1992, Lavigne 1996, Bowen 1997, Trites et al. 1997, Yodzis 1998, Goldsworthy et al. 2003, Ruzicka et al. 2013). The argument that marine mammals can limit the growth and/or recovery of prey populations that are also commercially harvested has led to calls for culls of marine mammals (e.g. Wickens et al. 1992, FRCC 2011). However, where the effects of a marine mammal cull on fisheries was analysed (proposed cull of Cape fur seals Arctocephalus pusillus pusillus to enhance Cape hakes Merluccius capensis and $M$. paradoxus fisheries off the South African coast), sim- 
ulation studies indicated that a cull would likely be detrimental to fisheries yields (Punt \& Butterworth 1995, Yodzis 1998).

The northern cod stock off eastern Newfoundland and Labrador (Northwest Atlantic Fisheries Organization [NAFO] Divisions 2J3KL; Fig. 1) was by far the largest of the Atlantic Canadian stocks. Continued over-exploitation led to a stock collapse in the early 1990s (Hutchings \& Myers 1994), although environmental variability may have played an important role in this collapse (Drinkwater 2002, Halliday \& Pinhorn 2009). Despite $20 \mathrm{yr}$ of markedly reduced fishing effort, this stock has not recovered to pre-collapse levels. This lack of recovery has been attributed to the high levels of mortality that the offshore components of the stock have experienced throughout the mid-1990s and the early 2000s (DFO 2008b). Shelton et al. (2006) argued that fishing mortality under low productivity during the last half of the 1990s delayed the recovery of the stock. Potential hypotheses to explain the elevated natural mortality include diseases and parasites, contaminants, starvation and/or poor condition, changes in life history and predation by marine mammals, all with differing degrees of

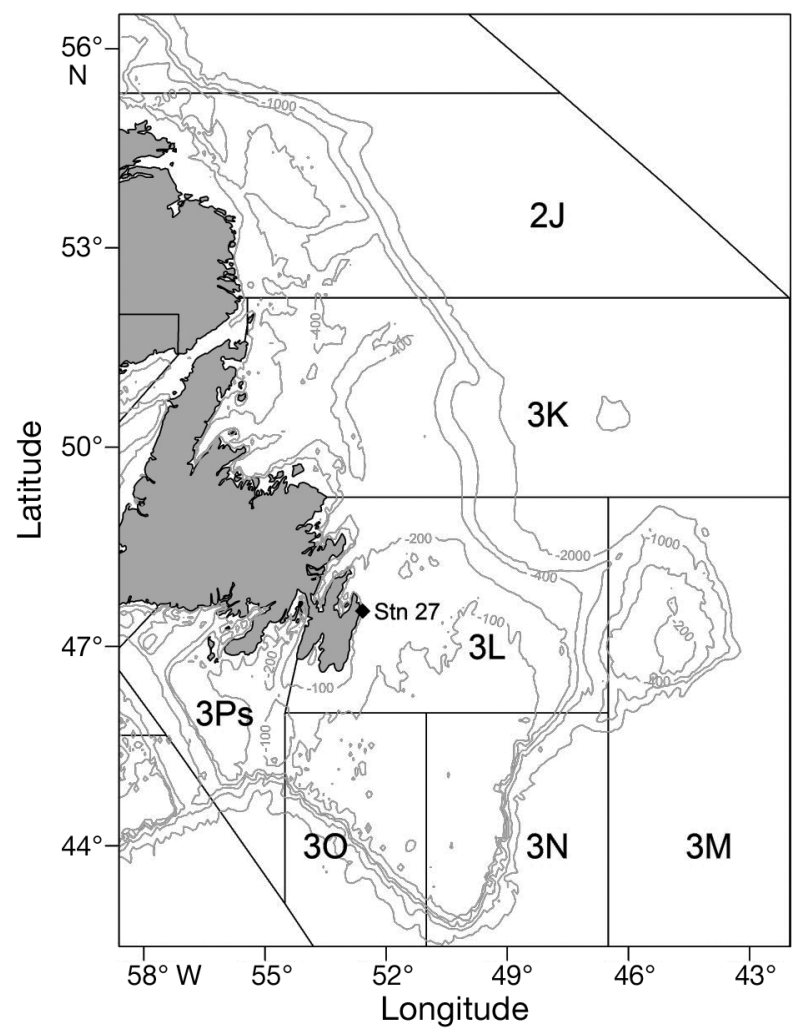

Fig. 1. Study area. The northern cod inhabits the Northwest Atlantic Fisheries Organization (NAFO) Divisions 2J3KL. The position of Stn 27, where bottom temperature was recorded, is indicated. Bathymetry contours are shown in meters empirical support (summary in DFO 2009). An explanation commonly offered for the non-recovery of the stock is predation by harp seals, either based on model simulations (Bundy 2001) or on a lack of evidence that the high mortality experienced may be explained differently (e.g. DFO 2003a,b).

Harp seals are the most abundant marine mammal in the Northwest Atlantic, with an estimated population size of 7.1 million animals (Hammill et al. 2013). Harp seals undergo extensive migrations between the Arctic, where they summer, and the waters off Newfoundland and Labrador and the Gulf of St Lawrence, where they whelp and moult during the winter, thus effectively spending half the year in the area of interest (Stenson \& Sjare 1997). In Newfoundland waters, they feed on an array of prey species, including cod. Although cod is neutrally or negatively selected by harp seals (Lawson et al. 1998a), consumption estimates are in the order of hundreds of thousand tons annually (Stenson 2012).

Capelin Mallotus villosus is the core forage species in this ecosystem (Lavigne 1996). It is an energy rich fish (Lawson et al. 1998b) that has historically been the cod's main prey item (Lilly 1987, 1991). In 1991, there was a major reduction in capelin biomass in the Newfoundland-Labrador shelf, and to date the stock has not recovered (DFO 2010). In addition, spawning was protracted and delayed up to $4 \mathrm{wk}$ (Nakashima \& Wheeler 2002, DFO 2010), size and age at maturity and somatic condition were reduced (Carscadden \& Nakashima 1997, Carscadden \& Frank 2002), vertical distribution shifted (Mowbray 2002) and episodic occurrences outside of their normal range on the Scotian Shelf and Flemish Cap were recorded (Frank et al. 1996, Carscadden \& Nakashima 1997). Buren et al. (2014) proposed that the capelin biomass trajectory was driven by a regime shift and the dynamics of seasonal sea ice via the synchrony of the phytoplankton bloom and the emergence of Calanus finmarchicus (capelin's main prey) from diapause.

The abundance of capelin has been related to the fecundity of cod in the Grand Banks (NAFO Divisions 3NO, Fig. 1) (Rideout \& Morgan 2010), and diets rich in capelin have been correlated with high body and liver condition, and increased spawning potential of cod, thus suggesting that capelin is key to the productivity and recovery potential of the northern cod (Rose \& O'Driscoll 2002, Sherwood et al. 2007). However, Lilly et al. (2003) reported that mean somatic condition of northern cod in the northern portion of the range (NAFO Divisions 2J3K) declined in the early 1990s and returned to approximately normal during the second half of the decade, while the mean 
somatic condition in the southern portion (NAFO Division 3L) remained relatively unchanged.

The objectives of this study were to test competing hypotheses on the relative contributions of fisheries removals, predation by harp seals, and food availability (as indexed by capelin) on the lack of recovery and dynamics of the northern cod stock, and to explore the mechanisms through which the main drivers may affect the stock's dynamics.

\section{MATERIALS AND METHODS}

\section{The data}

The time series of Atlantic cod biomass to which the model was fitted was based on the research vessel (RV) survey index (Fig. 2a) derived from the Fisheries and Oceans Canada (DFO) annual autumn bottom trawl surveys of Northwest Atlantic Fisheries Organization (NAFO) Divisions 2J, 3K and 3L (Fig. 1).
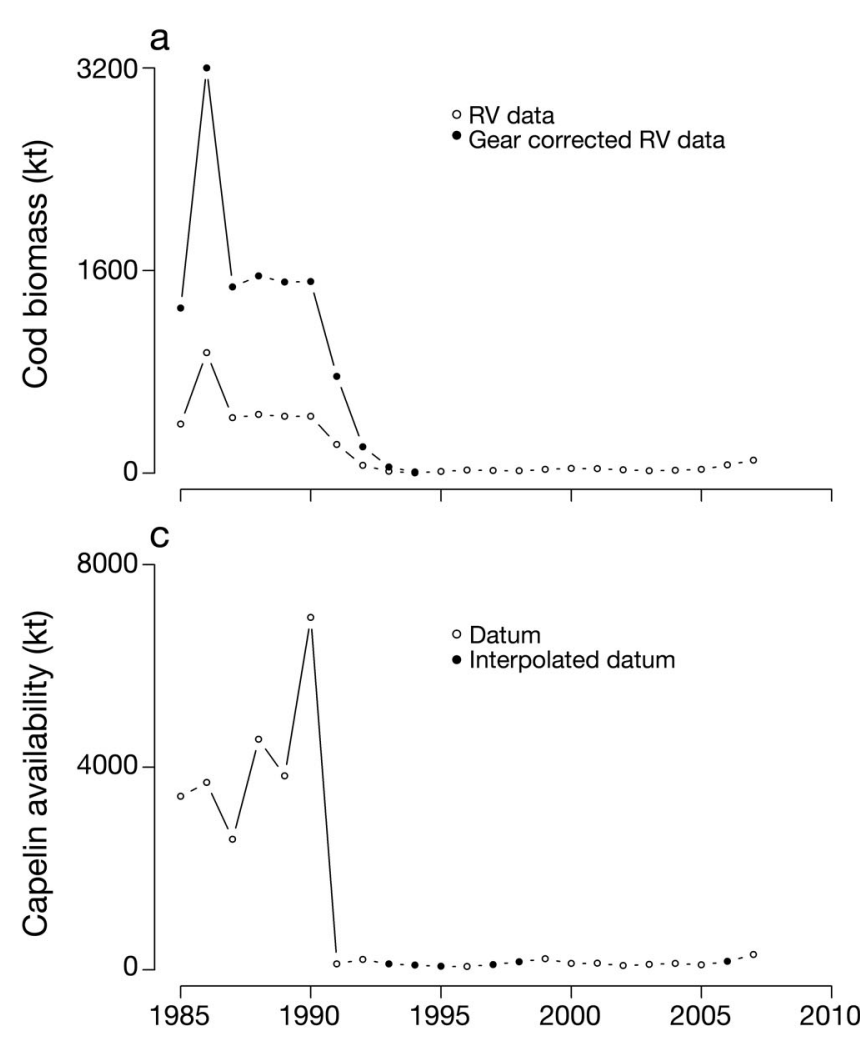

In 1995, DFO changed the survey gear from an Engel otter trawl to a Campelen shrimp trawl, and comparative fishing trials were carried out to develop conversion factors for catches at length (Warren 1997, Warren et al. 1997). As our model is biomass-based, we do not need to make the assumptions these authors made to develop these length-based conversions, and therefore we used the data from the comparative fishing trials to produce a biomass-based conversion factor. The median ratio of Campelen/ Engel swept area biomass was 3.3642 (Fig. 3); therefore, survey data prior to 1995 was corrected using this factor, producing a 'gear corrected' time series (Fig. 2a). The entire cod biomass 'gear corrected' time series was assumed to be an index with a time invariant catchability, $q$. We also used the converted time series using the length-based conversions (Warren 1997, Warren et al. 1997), and the results were qualitatively identical (results not shown).

Fisheries catches of Atlantic cod for NAFO Divisions 2J3KL (Fig. 2b) were obtained from Brattey et al. (2011).
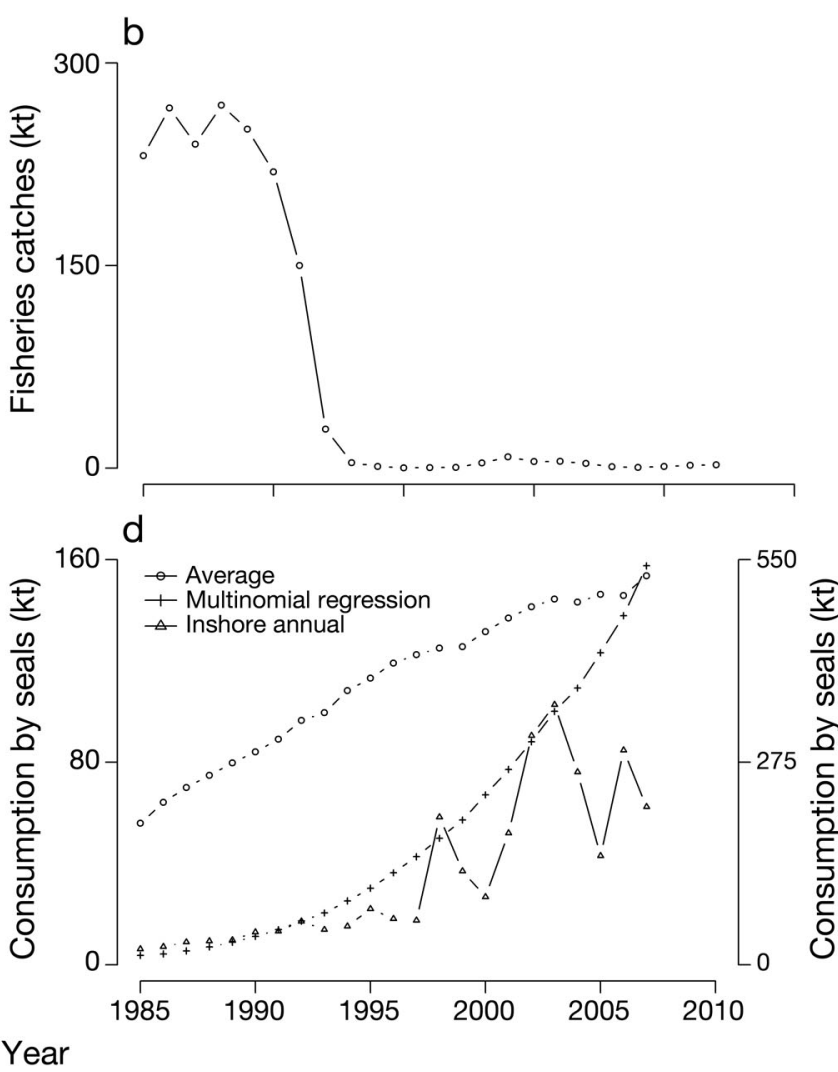

Fig. 2. Input data for the model: (a) Atlantic cod biomass index in Northwest Atlantic Fisheries Organization (NAFO) Divisions 2J3KL, derived from RV surveys and corrected due to change in gear using the biomass conversion factor developed in this study (see Fig. 2); (b) fisheries catches of Atlantic cod in NAFO Divisions 2J3KL; (c) acoustic estimate of capelin availability index from the Department of Fisheries and Oceans Canada (DFO) annual spring survey in Division 3L; and (d) Atlantic cod consumption by harp seals, estimated using average (left axis), multinomial regression and inshore annual diets (both on right axis) 


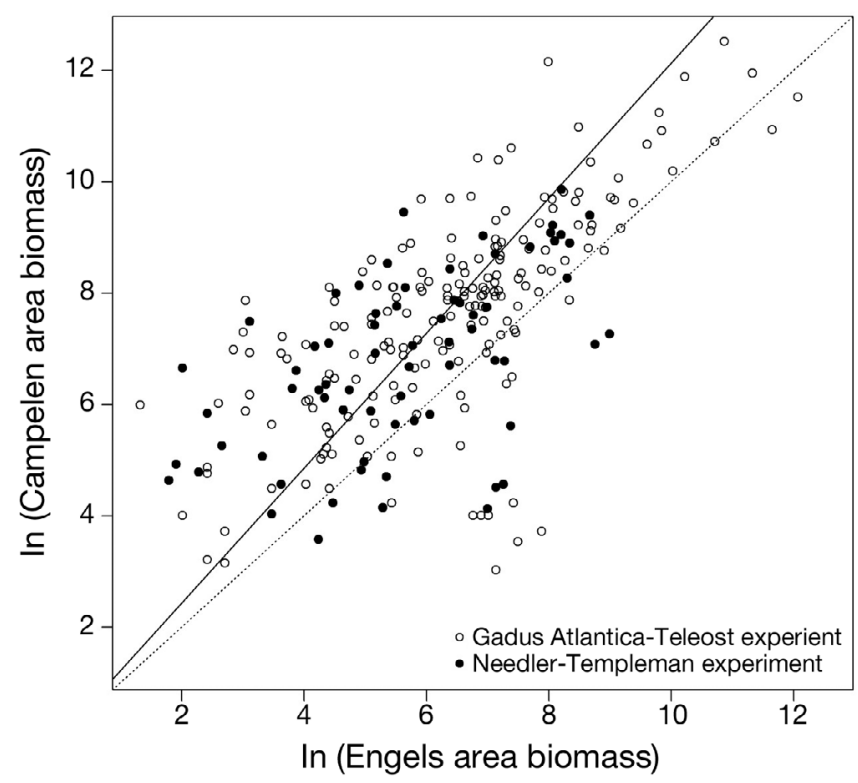

Fig. 3. Paired tows from comparative fishing trials to assess differences in catchability between Engels and Campelen gears and fishing procedures. Dotted line represents a 1:1 relationship, solid line has a slope of $\ln (3.3642)$

Acoustic estimates of capelin availability (Miller 1997, DFO 2010, Mowbray 2012) from the DFO annual spring survey of NAFO Division 3L were used as an index of capelin availability (Fig. 2c). Since this survey has only partial coverage of the entire stock area, the estimates it provides are considered to be minimum biomass estimates (DFO 2010, 2013). Nonetheless, the estimates from this survey allow enough resolution to track cohorts (Mowbray 2012, DFO 2013). In addition, preliminary analyses suggest an overall coherence between the capelin biomass trends over time estimated from the spring acoustic surveys and the bottom trawl surveys that DFO carries out during the fall in NAFO Divisions 2J3KL using the Campelen trawl (M. Koen-Alonso unpubl. data). Therefore the relative biomass index for the capelin stock in the region can be considered a reliable index of abundance for the 2J3KL capelin stock (Mowbray 2012).

Capelin surveys were carried out during the years 1985 to 1992, 1996, 1999 to 2005, and 2007. For those years when a capelin survey was not carried out, the value of biomass was linearly interpolated between the 2 surveys closest in time.

Prey (Atlantic cod) consumption by Northwest Atlantic harp seals (Fig. 2d) was estimated using a bioenergetics model that incorporates population size, seasonal and spatial distribution, energy requirements, energy content of prey, and geographi- cal and seasonal variation in diet composition (Stenson 2012). Uncertainty in each of these components carries through into the consumption estimates. Of these factors, the biggest contributor to uncertainty of Atlantic cod consumption is diet composition (Shelton et al. 1997). To account for this uncertainty, we estimated cod consumption using 3 different diet compositions as inputs for the consumption model and, during fitting of the cod dynamic model, we allowed the consumptions to scale up or down via a scaling parameter. In this fashion, we allowed cod consumption to take 3 different shapes (Fig. 2d) and cover a wide range of potential consumption magnitudes. The diet descriptions used as input for the consumption model were (1) 'average' description, (2) reconstructed diet taking a multinomial regression approach (Koen-Alonso et al. 2009), and (3) 'inshore annual'. Diet composition (and prey consumption) is described in 8 spatio-temporal blocks; prey consumption is then integrated to provide annual consumption in the study area. The blocks are defined to contemplate seasonal (summer vs. winter) and spatial differences in diet. Geographical variability in diet composition is considered in terms of both latitudinal (NAFO Divisions 2J3K vs. Division 3L) and depth related (inshore vs. offshore) differences. The 'average' description considers diet variability in the 8 blocks described above, but it does not allow for inter-annual differences in the diet, which masks potential changes in diet over time. The 'multinomial regression' approach fills in data gaps and produces yearly estimates of diet composition for each of the area/season blocks. The resulting diet estimate yielded a larger proportion of cod in the offshore diet than was seen in the raw data. Given the weight that the offshore area bears ( 90\% offshore vs. $\sim 10 \%$ inshore) in the consumption, this resulted in likely overestimation of the total cod consumption. The diet data were collected annually in nearshore areas from 1982 to 2008. The 'inshore annual' diet description considers yearly differences in diet composition in the inshore areas, and assumes a constant diet composition in the offshore area. Sample sizes in the offshore area are not sufficient to resolve inter-annual variability. This description led to cod consumption that had greater inter-annual variability than the other 2 cases (Fig. 2d).

\section{The model}

We implemented a bioenergetic-allometric cod biomass dynamic model (Yodzis \& Innes 1992): 


$$
\frac{\mathrm{d} B_{\mathrm{cod}}}{\mathrm{d} t}=B_{\mathrm{cod}, t}\left(-T+P_{t}\right)-L_{t}
$$

where $\frac{\mathrm{d} B_{\mathrm{cod}}}{\mathrm{d} t}$ is the rate of change of cod biomass, $B_{\mathrm{cod}, t}$ is the cod stock biomass at time $t, T$ is mass-specific respiration rate of the population, $P_{t}$ is a massspecific gross production rate at the metabolizable level at time $t$ (i.e. the net production rate is given by $\left.\left[-T+P_{t}\right]\right)$, and $L_{t}$ is the rate of loss of biomass at time $t$ due to causes other than starvation. $P_{t}$ is expressed as:

$$
P_{t}=(1-\delta) J_{t}
$$

where $\delta$ is the fraction of ingested energy that is lost as feces and urine, and $J_{t}$ is the mass-specific ingestion rate of the population at time $t$. $J_{t}$ depends on the resource density, and we expressed it as a function of capelin availability at time $t, I_{\text {capelin, }}$. Note that the availability of capelin is used as a proxy for the quality of the prey field at time $t$, i.e. years when capelin biomass is high represent a time when a high quality prey field is available to cod:

$$
J_{t}=J_{\max } \frac{I_{\text {capelin }, t}^{2}}{I_{0}^{2}+I_{\text {capelin }, t}^{2}}
$$

where the constant, $J_{\max }$ is the asymptotic saturation rate of ingestion, and $I_{0}$ is the resource density at which half the saturation ingestion rate is attained (half-saturation density). Given that the value of the exponent of $I_{\text {capelin, } t}$ is 2 , this ingestion rate has the form of a Holling Type III functional response.

The biomass losses of the population at time $t_{t} L_{t}$ were expressed as the sum of natural mortality $m B_{\text {cod }, t}^{\psi}$, consumption by harp seals $\left(H_{\text {seal }, t}\right)$ and fisheries catches $\left(H_{\text {fisheries }, t}\right)$ :

$$
L_{t}=m B_{\mathrm{cod}, t}^{\psi}+H_{\text {seal }, t}+H_{\text {fisheries }, t}
$$

We fitted the model with 2 different types of natural mortality: linear ( $\psi=1$; density-independent) and quadratic $(\psi=2$; density-dependent).

The constants $T$ and $J_{\max }$ were calculated as:

$$
T=a_{T}\left(\bar{w}_{\text {cod }}\right)^{-0.25}
$$

where $\bar{W}_{\text {cod }}$ is the average body mass of an individual cod and $a_{T}$ is the allometric coefficient of the massspecific respiration rate of ectothermic vertebrates (Yodzis \& Innes 1992), and

$$
J_{\max }=a_{J}\left(\bar{W}_{\text {cod }}\right)^{-0.25}
$$

where $a_{J}$ is the allometric coefficient of the maximum physiological capacity to metabolize food of ectothermic vertebrates (Yodzis \& Innes 1992). We assumed $\bar{w}_{\text {cod }}=1 \mathrm{~kg}$.
Thus, the cod biomass dynamic model consists of 2 equations: the first is the dynamic equation for which the full expression is:

$$
\begin{aligned}
& \frac{\mathrm{d} B_{\mathrm{cod}}}{\mathrm{d} t}= \\
& \quad B_{\mathrm{cod}, t}\left[-a_{T}\left(\bar{W}_{\mathrm{cod}}\right)^{-0.25}+(1-\delta) a_{J}\left(\bar{W}_{\mathrm{cod}}\right)^{-0.25} \frac{I_{\text {capelin }, t}^{2}}{I_{0}^{2}+I_{\text {capelin }, t}^{2}}\right] \\
& -m B_{\mathrm{cod}, t}^{\psi}-\theta H_{\text {seal }, t}-H_{\text {fisheries }, t}
\end{aligned}
$$

where $\theta$ is a scaling parameter for the time series of consumption by harp seals.

The second equation relates the index of cod biomass from the survey, $I_{\text {cod, }, t}$ with the stock biomass at time $t, B_{\text {cod, } t}$ through $q$ :

$$
B_{\mathrm{cod}, t}=\frac{I_{\mathrm{cod}, t}}{q}
$$

Thus, the model has estimable parameters $q, m, I_{0}, \delta$, $\theta$ and an initial cod stock biomass $\left(B_{\text {cod, } 1985}\right)$ while $H_{\text {seal, }, t}$ $H_{\text {fisheries }, t}$ and $I_{\text {capelin, } t}$ are external forcers (Fig. 2).

\section{Model implementation}

The model was fitted by minimizing the log-likelihood function. A lognormal observation error was assumed.

The model was written in Fortran 77. The ordinary differential equation (Eq. 7) was solved using the Runge-Kutta method (subroutine IVMRK in IMSL 2006). In order to achieve global convergence, minimization of the model's log-likelihood function was performed using the Enhanced Simulated Annealing (ESA) algorithm (Siarry et al. 1997), implemented in a multi-start scheme where each model was run 100 times, starting each run from a random point within the possible parameter space.

In order to run, the model requires a complete set of predictor variables for every year in the time series. Linearly interpolated capelin biomass values are used as input, and will affect the model behaviour. In order to reduce (but not fully eliminate) the impact of these interpolated values, we estimated model parameters in 2 ways, by defining 2 alternative likelihood functions:

(1) 'full likelihood': all available survey indices of cod biomass within the 1985 to 2007 period were included in the calculation of the likelihood, and

(2) 'restricted likelihood': only survey indices of cod biomass corresponding to years within the 1985 to 2007 period when actual survey-based capelin data was available were included in the calculation of the likelihood. 
Even though interpolated capelin values are always used to fit the model, the implementation of the restricted likelihood focuses the parameter estimation process on those years which have a full suite of drivers available, and reduces the influence of mismatches between cod observations and model prediction for those years without actual capelin data. The assumption here is that any 'misdirection' occurring because of the interpolated capelin will affect more severely the year for which the capelin was interpolated than any subsequent year. Thus, a set of results is presented for the 'full likelihood' and a second set for the 'restricted likelihood' models. These are not directly comparable because the cod biomass data set used to estimate the parameters of the latter models is a subset of the larger data set used to estimate the parameters of the former models.

\section{Model comparison and selection}

On the basis of the generic model (Eq. 7), scenarios were explored by fitting different versions to the observed DFO RV survey series for northern cod (Table 1). These scenarios resulted from a combination of (1) removing each forcer from the model independently, and (2) using the different estimates of harp seal consumption derived from the 3 diet descriptions considered. In addition, due to their high uncertainty, consumption time series were allowed to scale up or down according to a scaling parameter $(\theta)$ estimated during the fitting process. Each scenario represents an alternative hypothesis on which factors drive the biomass dynamics of the cod stock.

Akaike's information criterion corrected for sample size (AICc) (Burnham \& Anderson 2002) was used to select the model that provided the best fit. Models that deserved further exploration were identified through the delta $\mathrm{AICc}\left(\Delta \mathrm{AICc}_{i}\right)$ (Burnham \& Anderson 2002). As a general rule, models having $\Delta \mathrm{AICC}_{i}>$ 10 have either essentially no empirical support, or at least those models fail to explain some substantial explainable variation in the data (Burnham \& Anderson 2002), and may thus be omitted from further consideration. The relative empirical support the models had was assessed using evidence ratios $\left(E_{\min , i}\right)$, which is a measure of the support that a given model $i$ has on the data relative to the best model (Anderson 2008).

We carried out this exercise considering 2 different time spans: using data from 1985 to 2007 as a representation of the cod biomass dynamics, and data from 1992 to 2007 to specifically pinpoint the drivers of the cod dynamics during the period of non-recovery.

\section{Somatic condition}

To explore the mechanisms through which food availability may impact the dynamics of the cod stock, we compared the distribution curves of somatic con-

Table 1. Scenarios used to test the effects of the proposed drivers on the dynamics of the northern cod stock and the parameters that are estimated in each case $(q$ : catchability; $m$ : natural mortality; $\delta$ : fraction of ingested energy lost as feces and

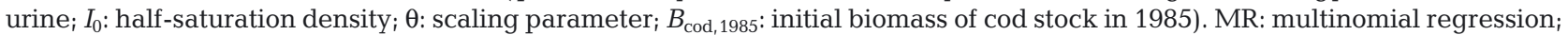
ASC: adjusted seal consumption

\begin{tabular}{|c|c|c|c|}
\hline Scenario & Cod stock drivers & Diet description & Estimated parameters \\
\hline All effects, average & Capelin, fisheries, seals & Average & $q, m, \delta, B_{\mathrm{cod}, 1985,} I_{0}$ \\
\hline All effects, average, ASC & Capelin, fisheries, seals & Average & 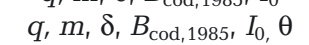 \\
\hline All effects, MR & Capelin, fisheries, seals & MR & $q, m, \delta, B_{\mathrm{cod}, 1985,} I_{0}$ \\
\hline All effects, MR, ASC & Capelin, fisheries, seals & MR & $q, m, \delta, B_{\mathrm{cod}, 1985,} I_{0}, \theta$ \\
\hline All effects, annual inshore & Capelin, fisheries, seals & Annual inshore & $q, m, \delta, B_{\text {cod }, 1985,} I_{0}$ \\
\hline All effects, annual inshore, ASC & Capelin, fisheries, seals & Annual inshore & 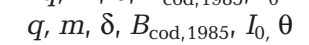 \\
\hline No capelin, average, ASC & Fisheries, seals & Average & $q, m, \delta, B_{\mathrm{cod}, 1985,} I_{0}, \theta$ \\
\hline No fishery, average, ASC & Capelin, seals & Average & $q, m, \delta, B_{\mathrm{cod}, 1985,} I_{0}, \theta$ \\
\hline No capelin, MR, ASC & Fisheries, seals & $\mathrm{MR}$ & $q, m, \delta, B_{\mathrm{cod}, 1985,} I_{0,} \theta$ \\
\hline No fishery, MR, ASC & Capelin, seals & $\mathrm{MR}$ & $q, m, \delta, B_{\mathrm{cod}, 1985,} I_{0}, \theta$ \\
\hline No capelin, annual inshore, ASC & Fisheries, seals & Annual inshore & $q, m, \delta, B_{\mathrm{cod}, 1985,} I_{0,} \theta$ \\
\hline No fishery, annual inshore, ASC & Capelin, seals & Annual inshore & $q, m, \delta, B_{\mathrm{cod}, 1985,} I_{0,}, \theta$ \\
\hline No seals & Capelin, fisheries & NA & $q, m, \delta, B_{\mathrm{cod}, 1985}, I_{0}$ \\
\hline Only seals, average, ASC & Seals & Average & $q, m, \delta, B_{\mathrm{cod}, 1985, \theta}$ \\
\hline Only seals, MR, ASC & Seals & $\mathrm{MR}$ & $q, m, \delta, B_{\mathrm{cod}, 1985, \theta}$ \\
\hline Only seals, annual inshore, ASC & Seals & Annual inshore & $q, m, \delta, B_{\mathrm{cod}, 1985,} \theta$ \\
\hline Only capelin & Capelin & NA & $q, m, \delta, B_{\mathrm{cod}, 1985,} I_{0}$ \\
\hline Only fisheries & Fisheries & NA & $q, m, \delta, B_{\mathrm{cod}, 1985}$ \\
\hline
\end{tabular}


dition from 1978 until 2006. We used Fulton's condition factor $(K)$ as indicator of cod condition. It was expressed as $K=100 W / L^{3}$, where $W$ is total weight (g) and $L$ is fish length $(\mathrm{cm})$.

Atlantic cod exhibit marked seasonal variations in energy reserves, with maximum levels reached in fall and minimum levels in spring during the spawning period. Given that the research surveys occur in the fall, data collected during these periods reflect top condition. We used Lambert's $(2011,2012)$ equation that relates $K$ calculated from total mass in January to $K$ calculated from somatic mass in the following May in the northern Gulf of St. Lawrence to estimate a condition factor for the spring period $\left(K_{\mathrm{s}}\right)$, the most critical time of the year. The condition of Atlantic cod in Newfoundland remains virtually constant during the fall and into January (Mello \& Rose 2005), thus allowing the use of fall condition as independent variable in Lambert's $(2011,2012)$ equation.

We present the distribution of $K_{\mathrm{s}}$ and use as benchmarks for comparisons threshold values found in starvation and feeding experiments (Lambert \& Dutil 1997). In these laboratory settings, prolonged fasting resulted in condition factors below 0.7 and feeding in values above 0.85 (Lambert \& Dutil 1997). We restricted the size range of fish analyzed to between 30 and $55 \mathrm{~cm}$, the size range used in the starvation experiments (Lambert \& Dutil 1997).

Fulton's condition factor suffers from an important shortcoming: the value of $K$ is dependent on the length of the fish, given that an exponent of 3 is assumed in the length-weight relationship; and instances where that is true are rare. To overcome this, it is common practice to calculate a relative condition factor, $K_{\mathrm{r}}=W / \hat{W}$, where $\hat{W}$ is the predicted body weight from a lengthweight relationship (Le Cren 1951). We calculated $K_{\mathrm{r}}$ and the patterns obtained are identical to those observed when $K$ is examined. We therefore present the results only in terms of $K$.

\section{RESULTS}

\section{Model selection}

Model selection statistics for the time span 1985 to 2007 are presented in Tables 2 (restricted likelihood) and 3 (full likelihood), and for the time span 1992 to 2007 in Tables 4 (restricted likelihood) and 5 (full likelihood). Model fits are compared across scenarios and expressions of natural mortality $(\psi=1$ : density-independent or $\psi=2$ : density-dependent).

Only a few models had enough empirical support to deserve further consideration (i.e. $E_{\min , i}<10$ ), considering both the 1985 to 2007 and 1992 to 2007 time spans. For the 1985 to 2007 time span, only 2 models (out of 36) in the case of restricted likelihood (Table 2) and 3 in the case of the full likelihood (Table 3) had reasonable empirical support. For the 1992 to 2007 time span, 3 models in each likelihood considered had an $E_{\min , i}$ value smaller than 10 (Tables 4 \& 5). The rest of the models had very little empirical support and were therefore considered not to be valid depictions of cod biomass dynamics.

A clear pattern arises from examining the tables (Tables 2 to 5) concurrently: all models worth considering contained fishery removals and/or capelin availability, and none had consumption by harp seals as important drivers of the dynamics, considering the entire time period or only the period of non-recovery. Given that the patterns found during model selection were identical when considering both the entire time span and the time span for the non-recovery, we will hereafter discuss only the models fit to the entire time span (1985 to 2007) as these are better representations of the cod biomass dynamics.

Table 2. Model selection statistics for models fitted considering the restricted likelihood, for the period 1985 to 2007 . Model fits are compared across scenarios and types of natural mortality $(\psi=1$ : linear mortality, $\psi=2$ : quadratic mortality). $\triangle$ AICc: delta Akaike information criterion corrected for sample size; $E_{\min , i}$ : evidence ratio; $p$ : number of estimated parameters; MR: multinomial regression; ASC: adjusted seal consumption

\begin{tabular}{|c|c|c|c|c|c|}
\hline \multirow[t]{2}{*}{ Scenario } & \multirow[t]{2}{*}{$p$} & \multicolumn{2}{|c|}{$-\Delta \mathrm{AICC}-$} & \multicolumn{2}{|c|}{$-E_{\min , i}$} \\
\hline & & $\psi=1$ & $\psi=2$ & $\psi=1$ & $\psi=2$ \\
\hline No seals & 5 & 28.9 & 0 & $2 E+06$ & 1 \\
\hline Only capelin & 5 & 33.2 & 3.1 & $2 \mathrm{E}+07$ & 5 \\
\hline No fishery, average, ASC & 6 & 50.2 & 13.0 & $8 \mathrm{E}+10$ & 674 \\
\hline All effects, average, ASC & 6 & 44.7 & 13.4 & $5 E+09$ & 798 \\
\hline All effects, annual inshore, ASC & 6 & 49.9 & 17.7 & $7 \mathrm{E}+10$ & $7 \mathrm{E}+03$ \\
\hline No fishery, annual inshore, ASC & 6 & 53.5 & 19.6 & $4 \mathrm{E}+11$ & $2 \mathrm{E}+04$ \\
\hline All effects, average & 5 & 62.8 & 21.9 & $4 \mathrm{E}+13$ & $6 \mathrm{E}+04$ \\
\hline All effects, MR, ASC & 6 & 53.2 & 24.7 & $4 \mathrm{E}+11$ & $2 \mathrm{E}+05$ \\
\hline Only fisheries & 4 & 25.7 & 25.6 & $4 \mathrm{E}+05$ & $4 \mathrm{E}+05$ \\
\hline No fishery, MR, ASC & 6 & 59.2 & 26.8 & $7 \mathrm{E}+12$ & $7 \mathrm{E}+05$ \\
\hline All effects, MR & 5 & 68.6 & 36.2 & $8 \mathrm{E}+14$ & $7 \mathrm{E}+07$ \\
\hline All effects, annual inshore & 5 & 65.5 & 36.8 & $2 \mathrm{E}+14$ & $1 \mathrm{E}+08$ \\
\hline No capelin, average, ASC & 5 & 40.3 & 40.5 & $6 E+08$ & $6 \mathrm{E}+08$ \\
\hline Only seals, average, ASC & 5 & 45.3 & 41.0 & $7 E+09$ & $8 \mathrm{E}+08$ \\
\hline No capelin, annual inshore, ASC & 5 & 45.0 & 43.3 & $6 \mathrm{E}+09$ & $2 \mathrm{E}+09$ \\
\hline Only seals, annual inshore, ASC & 5 & 48.6 & 45.1 & $4 \mathrm{E}+10$ & $6 \mathrm{E}+09$ \\
\hline No capelin, MR, ASC & 5 & 49.0 & 48.2 & $4 \mathrm{E}+10$ & $3 \mathrm{E}+10$ \\
\hline Only seals, MR, ASC & 5 & 54.2 & 49.0 & $6 E+11$ & $4 \mathrm{E}+10$ \\
\hline
\end{tabular}


Table 3. Model selection statistics for models fitted considering the full likelihood, for the period 1985 to 2007. Model fits are compared across scenarios and types of natural mortality ( $\psi=1$ : linear mortality, $\psi=2$ : quadratic mortality). $\triangle \mathrm{AICc}$ : delta Akaike information criterion corrected for sample size; $E_{\min , i}$ : evidence ratio; $p$ : number of estimated parameters; MR: multinomial regression; ASC: adjusted seal consumption

\begin{tabular}{|c|c|c|c|c|c|}
\hline \multirow[t]{2}{*}{ Scenario } & \multirow[t]{2}{*}{$p$} & \multirow{2}{*}{\multicolumn{2}{|c|}{$\begin{array}{l}-\Delta \mathrm{AICc}- \\
\psi=1 \quad \psi=2\end{array}$}} & \multicolumn{2}{|c|}{$-E_{\min , i} \longrightarrow$} \\
\hline & & & & $\psi=1$ & $\psi=2$ \\
\hline Only fisheries & 4 & 1.4 & 0 & 2 & 1 \\
\hline No seals & 5 & 4.7 & 3.1 & 10.5 & 4.7 \\
\hline Only capelin & 5 & 22.7 & 5.5 & 9.E+ 04 & 15.7 \\
\hline No capelin, average, ASC & 5 & 19.4 & 13.0 & 2.E+04 & 667.5 \\
\hline All effects, average, ASC & 6 & 17.4 & 13.8 & 6. $E+03$ & 986.2 \\
\hline No fishery, average, ASC & 6 & 37.0 & 16.0 & 1.E+08 & 3. $E+03$ \\
\hline All effects, MR, ASC & 6 & 26.2 & 17.4 & $5 . E+05$ & $6 . \mathrm{E}+03$ \\
\hline No fishery, annual inshore, ASC & 6 & 43.2 & 17.4 & $2 . E+09$ & $6 . E+03$ \\
\hline All effects, annual inshore, ASC & 6 & 24.7 & 18.1 & 2.E+ 05 & $8 . E+03$ \\
\hline No fishery, MR, ASC & 6 & 45.0 & 18.5 & $6 . E+09$ & 1.E+ 04 \\
\hline All effects, average & 5 & 45.6 & 21.2 & 8.E+ 09 & 4.E+ 04 \\
\hline No capelin, MR, ASC & 5 & 26.3 & 22.3 & $5 . E+05$ & 7.E+ 04 \\
\hline All effects, annual inshore & 5 & 52.8 & 25.5 & 3. $E+11$ & 4.E+ 05 \\
\hline Only seals, average, ASC & 5 & 33.3 & 26.6 & 2.E+ 07 & $6 . E+05$ \\
\hline All effects, MR & 5 & 55.3 & 26.7 & 1. $E+12$ & $6 . E+05$ \\
\hline No capelin, annual inshore, ASC & 5 & 25.7 & 28.7 & 4.E+05 & 2. $E+06$ \\
\hline Only seals, annual inshore, ASC & 5 & 38.3 & 31.9 & $2 . E+08$ & 8.E+ +06 \\
\hline Only seals, MR, ASC & 5 & 41.3 & 34.3 & 9. $E+08$ & 3.E+ 07 \\
\hline
\end{tabular}

Table 4. Model selection statistics for models fitted considering the restricted likelihood, for the period 1992 to 2007 . Model fits are compared across scenarios and types of natural mortality $(\psi=1$ : linear mortality, $\psi=2$ : quadratic mortality). $\triangle$ AICc: delta Akaike information criterion corrected for sample size; $E_{\min , i}:$ evidence ratio; $p$ : number of estimated parameters; MR: multinomial regression; ASC: adjusted seal consumption

\begin{tabular}{|c|c|c|c|c|c|}
\hline \multirow[t]{2}{*}{ Scenario } & \multirow{2}{*}{$p$} & \multirow{2}{*}{\multicolumn{2}{|c|}{$\begin{array}{l}-\Delta \mathrm{AICc}- \\
\psi=1 \quad \psi=2\end{array}$}} & \multicolumn{2}{|c|}{$-E_{\min , i} \longrightarrow$} \\
\hline & & & & $\psi=1$ & $\psi=2$ \\
\hline Only capelin & 5 & 0 & 0.2 & 1 & 1.1 \\
\hline Only fisheries & 4 & 3.5 & 10.1 & 5.7 & 158.0 \\
\hline All effects, average & 5 & 8.3 & 42.2 & 62.4 & 1.E+ 09 \\
\hline No seals & 5 & 8.6 & 14.6 & 72.0 & 1.E+ 03 \\
\hline No capelin, average, ASC & 5 & 13.8 & 21.4 & 1.E+03 & 4.E+ 04 \\
\hline Only seals, average, ASC & 5 & 14.2 & 23.0 & 1.E+ 03 & 1.E+ 05 \\
\hline No capelin, annual inshore, ASC & 5 & 15.7 & 26.0 & 3.E+ 03 & 4.E+ 05 \\
\hline Only seals, annual inshore, ASC & 5 & 15.9 & 27.4 & 3.E+ 03 & 9. $\mathrm{E}+05$ \\
\hline All effects, average, ASC & 6 & 16.4 & 34.6 & 4.E+03 & 3.E+ 07 \\
\hline No fishery, average, ASC & 6 & 19.6 & 28.3 & 2.E+ 04 & 1.E+ 06 \\
\hline All effects, annual inshore, ASC & 6 & 19.8 & 39.5 & 2.E+04 & 4. E+ 08 \\
\hline Only seals, MR, ASC & 5 & 20.1 & 29.6 & 2.E+04 & 3.E+ 06 \\
\hline No capelin, MR, ASC & 5 & 20.2 & 30.1 & 2.E+04 & 4.E+ 06 \\
\hline No fishery, annual inshore, ASC & 6 & 22.0 & 35.7 & 6.E+ 04 & 6.E+ 07 \\
\hline All effects, MR, ASC & 6 & 24.0 & 43.8 & 2.E+ 05 & 3.E+ 09 \\
\hline No fishery, MR, ASC & 6 & 26.0 & 39.2 & 4.E+ 05 & 3. $E+08$ \\
\hline All effects, annual inshore & 5 & 27.4 & 44.2 & 9.E+ 05 & 4.E+ 09 \\
\hline All effects, MR & 5 & 33.9 & 48.0 & 2.E+07 & 3. $E+10$ \\
\hline
\end{tabular}

In the case of the restricted likelihood, the model that best fit the data was the 'No seals $(\psi=2)^{\prime}$ ' model, which had 5 times the weight of evidence relative to the second best model, 'Only capelin $(\psi=2)^{\prime}\left(E_{\text {noseals, onlycapelin }}=5\right)($ Table 2$)$.

In the case of the full likelihood, the best model was the 'Only fisheries $(\psi=2)^{\prime}$ model with double the weight of evidence as the second best 'Only fisheries $(\psi=1)$ ', and 5, 11 and 16 times the weight of evidence than the rest of the models with $\triangle \mathrm{AICC}<10$ : 'No seals $(\psi=2)^{\prime}$ ', 'No seals $(\psi=1)$ ' and 'Only capelin $(\psi=2)^{\prime}$, respectively (Table 3 ).

\section{Model fits}

The fit of the 2 models from the restricted likelihood set are virtually identical (Fig. 4), which indicates that capelin availability is the driver that has most influence on the behaviours of the models in this set. These models capture well the plateau in stock biomass during the 1980s and also track well the dynamics of the stock in the later part of the time series, when the biomass was very low but nevertheless shows a fair amount of variation (best seen in a logarithmic scale). The characteristic of the time series these models fail to represent well is the timing of the collapse during the early 1990s, predicting that the collapse would have occurred later than it actually did: the stock reached its minimum biomass in 1994, whereas the expected biomass under these models reaches its minimum in 1997. It is important to note, however, that during the 1990s there were several years (1993 to 1995, $1997,1998)$ when capelin surveys were not carried out, and given the influence that capelin availability has on the behaviour of these models it is not entirely unexpected that the stock biomass is not well captured during this period.

On the other hand, the fit of the 4 best models from the full likelihood set (Fig. 5) (those that include fisheries and/or capelin availability) are mainly driven by fisheries removals. This group of models predicted that the cod stock decreased since the beginning of the time series (earlier than it actually 
Table 5. Model selection statistics for models fitted considering the full likelihood, for the period 1992 to 2007. Model fits are compared across scenarios and types of natural mortality ( $\psi=1$ : linear mortality, $\psi=2$ : quadratic mortality). $\triangle$ AICc: delta Akaike information criterion corrected for sample size; $E_{\min , i}:$ evidence ratio; $p$ : number of estimated parameters; MR: multinomial regression; ASC: adjusted seal consumption

\begin{tabular}{|c|c|c|c|c|c|}
\hline \multirow[t]{2}{*}{ Scenario } & \multirow[t]{2}{*}{$p$} & \multirow{2}{*}{\multicolumn{2}{|c|}{$\begin{array}{l}-\Delta \mathrm{AICc}- \\
\psi=1 \quad \psi=2\end{array}$}} & \multicolumn{2}{|c|}{$-E_{\min , i}-$} \\
\hline & & & & $\psi=1$ & $\psi=2$ \\
\hline Only fisheries & 4 & 1.5 & 0 & 2.1 & 1 \\
\hline Only capelin & 5 & 7.8 & 0.5 & 50 & 1.3 \\
\hline No seals & 5 & 9.9 & 5.2 & 143 & 13 \\
\hline Only seals, average, ASC & 5 & 9.1 & 5.7 & 96 & 17 \\
\hline No capelin, average, ASC & 5 & 10.9 & 6.1 & 239 & 21 \\
\hline All effects, average, ASC & 6 & 11.7 & 7.1 & 347 & 35 \\
\hline No fishery, average, ASC & 6 & 14.4 & 7.4 & 1.E+ 03 & 41 \\
\hline All effects, annual inshore, ASC & 6 & 15.7 & 7.6 & 3. $E+03$ & 44 \\
\hline No fishery, annual inshore, ASC & 6 & 17.7 & 7.7 & 7. $E+03$ & 48 \\
\hline Only seals, annual inshore, ASC & 5 & 15.1 & 7.8 & 2.E+ 03 & 49 \\
\hline No capelin, annual inshore, ASC & 5 & 13.3 & 8.1 & 758 & 57 \\
\hline All effects, average & 5 & 43.9 & 8.4 & 3.E+ 09 & 65 \\
\hline Only seals, MR, ASC & 5 & 20.3 & 10.8 & 3. $E+04$ & 224 \\
\hline No capelin, MR, ASC & 5 & 20.4 & 11.3 & 3.E+ 04 & 283 \\
\hline No fishery, MR, ASC & 6 & 21.0 & 11.7 & 4.E+ 04 & 341 \\
\hline All effects, MR, ASC & 6 & 22.3 & 11.8 & 7.E+ 04 & 356 \\
\hline All effects, annual inshore & 5 & 45.4 & 26.6 & 7. $E+09$ & 6.E+ 05 \\
\hline All effects, MR & 5 & 51.3 & 31.3 & 1.E+11 & $6 . E+06$ \\
\hline
\end{tabular}

was observed. This group of models includes 2 models with density-independent and 2 with density-dependent mortality. The behaviour of these models is very similar; the most conspicuous difference between them is that the expected biomass at the beginning of the time series is larger in the models that show density dependence.

\section{Model projections and hindcast}

Using the maximum likelihood estimates from the best model in each set (restricted and full likelihood), and the data on fisheries removals and capelin availability, we produced forecasted stock biomass for the years 2008 to 2010 (Fig. 6). These 2 projections fail in opposite directions: the best model from the restricted likelihood set ('No seals') overestimates the stock biomass, whereas the best model from the restricted full set ('Only fisheries') did), but captured well the timing of the minimum during 1993 and 1994. The dynamics of the stock since the 1990s are not well captured by these models, as they predicted less inter-year variability than the dynamics of the stock might be driven by an interplay of both these variables, rather than being dominated by one as the projections represent. underestimates it (Fig. 6). This is an indication that

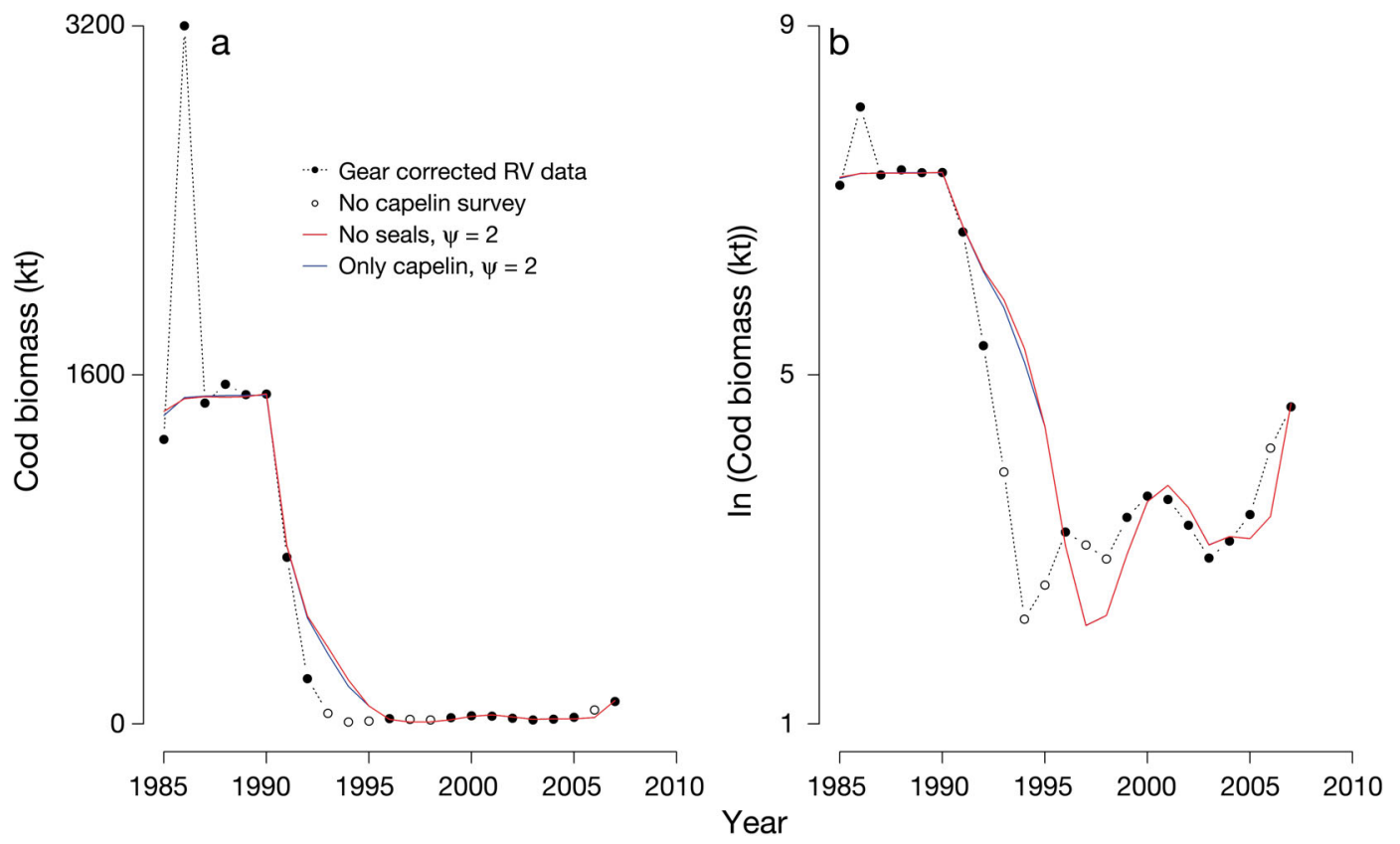

Fig. 4. Fit of the best 2 models of the restricted likelihood set, showing (a) cod stock biomass in arithmetic scale and (b) cod stock biomass in logarithmic scale. Filled circles denote years when a capelin survey was carried out and open circles years when a survey was not carried out. Models are listed in descending order of empirical support (see Table 2) 


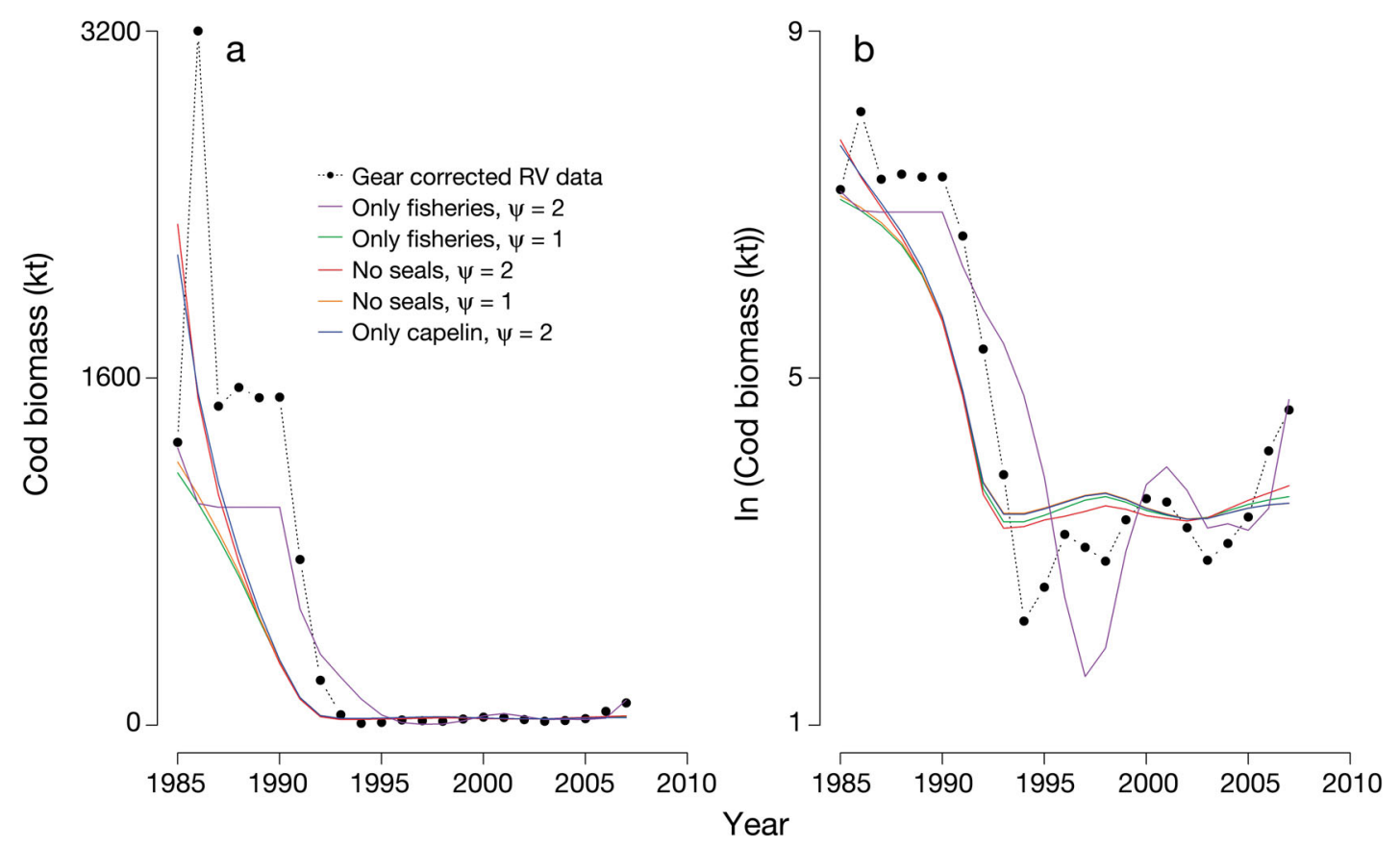

Fig. 5. Fit of the best 5 models of the full likelihood set, showing (a) cod stock biomass in arithmetic scale and (b) cod stock biomass in logarithmic scale. Models are listed in descending order of empirical support (see Table 5)

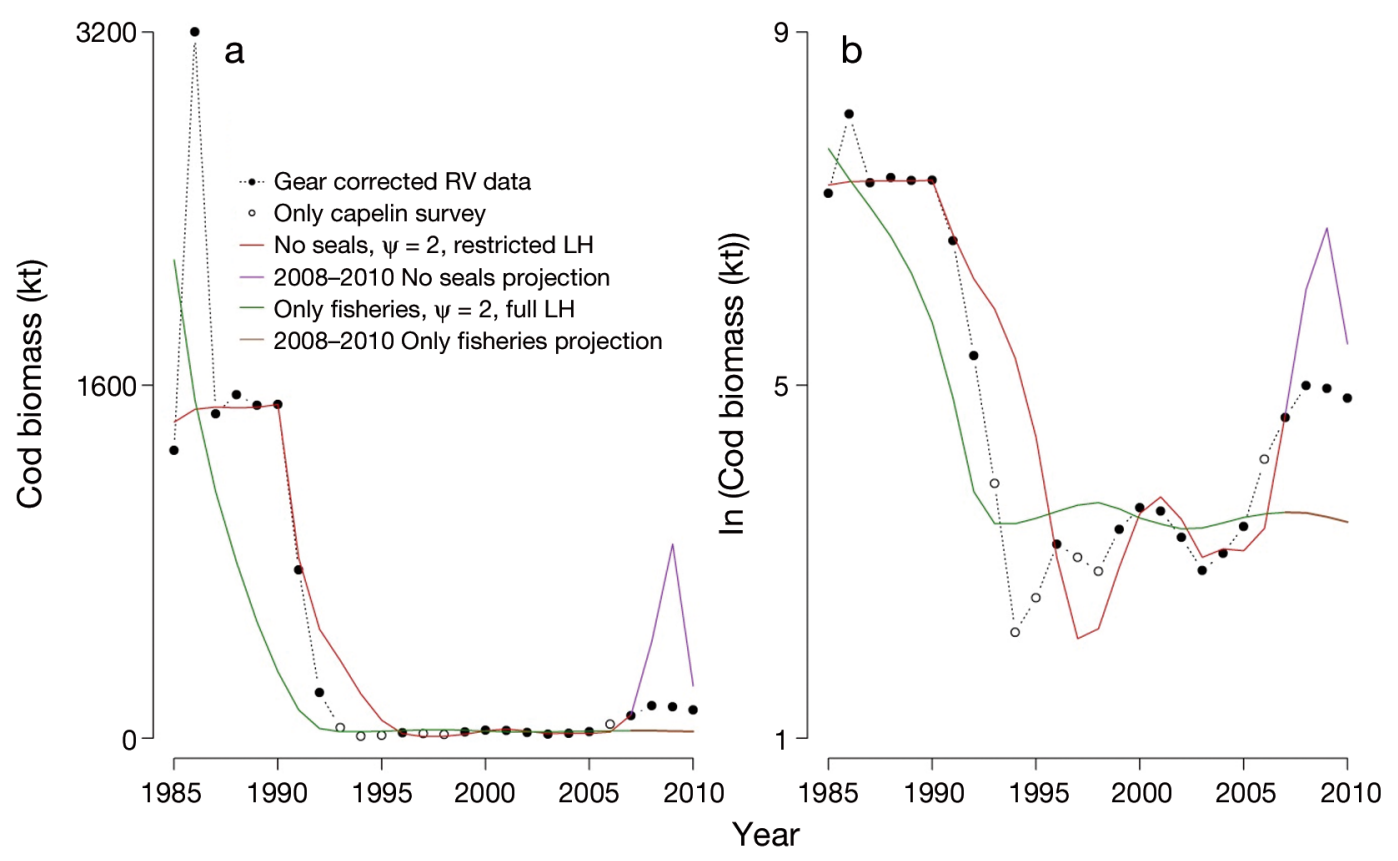

Fig. 6. Projection for 2008 to 2010 of the best model of the restricted 'No seals $(\psi=2)^{\prime}$ ' (red and purple lines) and full 'Only fisheries $(\psi=2)^{\prime}$ (green and brown lines) likelihood (LH) sets, showing (a) cod stock biomass in arithmetic scale and (b) cod stock biomass in logarithmic scale. Filled circles denote years when a capelin survey was carried out and open circles years when a survey was not carried out

\section{Balancing the effects of fisheries harvest and capelin availability on cod dynamics}

The parameter that controls the relative contribution of fisheries removals and food availability within the model is the half-saturation density, $I_{0}$. If $I_{0}$ is too low, then the ingestion rate is quickly saturated and the model does not respond to the availability of capelin: $I_{0}$ estimated in the 'No seals $(\psi=2)$ ' model of the full likelihood set was 11 kt (Fig. 7). If, on the 


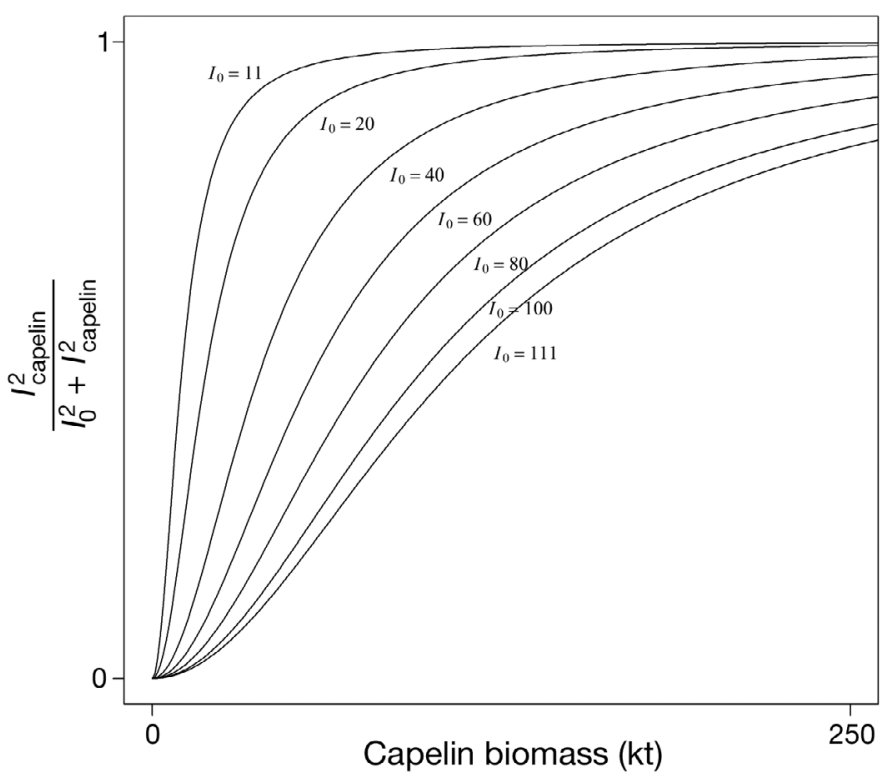

Fig. 7. Ingestion rate of Atlantic cod as a function of resource density and half-saturation density $\left(I_{0}\right)$

other hand $I_{0}$ is too large, the ingestion rate does not reach saturation and the model is very responsive to the capelin levels: $I_{0}$ estimated in the 'No seals $(\psi=2)$ ' model of the restricted likelihood set was $111 \mathrm{kt}$ (Fig. 7). We explored intermediate values of $I_{0}$ by creating a likelihood profile (Hilborn \& Mangel 1997), allowing $I_{0}$ to vary between 20 and 100 kt (Fig. 7). To break correlation among parameters, we fixed the value of $q$ at the level we observed in the 7 models discussed above, $q=1$. For each fixed level of $I_{0}$, we looked for the best fit and produced a forecast for 2008 to 2010, and a hindcast for 1969 to 1984. The capelin biomass used to produce these hindcasts was taken from the Buren et al. (2014) ice-capelin model. Hindcasts were contrasted with the output of the missing fish sequential population analysis (SPA) (Shelton \& Lilly 2000, Smedbol et al. 2002), which spans the years 1962 to 2001.

We found that at a level of $I_{0}=80 \mathrm{kt}$, the 2008 to 2010 predictions agree quite well with the observed level of stock biomass (Fig. 8). In addition, the hindcast agreed very well with the SPA in both the trends and the magnitudes of the stock biomass (Fig. 8). The major difference between these 2 is that the SPA predicts a biomass peak during the mid-1980s, whereas our model hindcast predicts a plateau throughout the 1980s, which is more consistent with the RV data. It is worth noting that both the SPA and our most parsimonious model predict lower stock biomass during the 1980s than the index derived from the RV survey. This is not unexpected given that the 'gear corrected' time series is an index, and thus it is concordance in trends rather than absolute values, which is most reassuring.

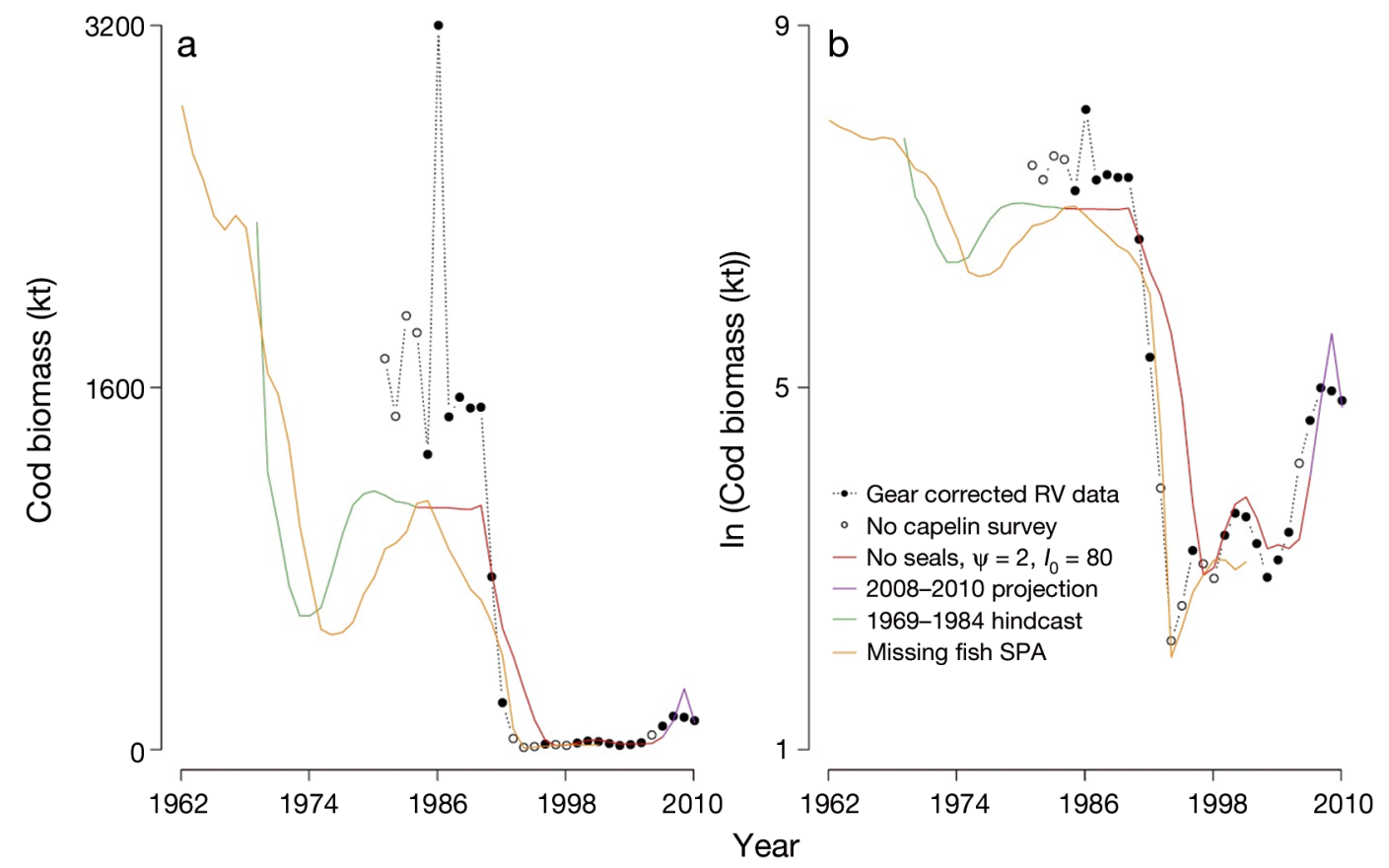

Fig. 8. Projection for 2008 to 2010 (purple line) and hindcast for 1969 to 1984 (green line) for the most parsimonious model 'No seals $\left(\psi=2, q=1, I_{0}=80\right.$ )' (red line), and output of the 'missing fish' sequential population analysis for the years 1962 to 2001 (orange line), showing (a) cod stock biomass in arithmetic scale and (b) cod stock biomass in logarithmic scale. Filled circles denote years when a capelin survey was carried out and open circles years when a survey was not carried out 


\section{Mortality}

We calculated the net losses at time $t$ from the model $\left(Z_{\text {model }}\right)$, and contrasted it to the total mortality rate of cod aged 4 to 6 calculated using data from the autumn RV surveys in the offshore of $2 \mathrm{~J} 3 \mathrm{KL}\left(Z_{\mathrm{RV}}\right)$ (DFO 2011b). $Z_{\text {model }}$ was estimated for the most parsimonious model, i.e. 'No seals $\left(\psi=2, q=1, I_{0}=80\right)$ ', and defined as:

$$
Z_{\text {model }}=\text { Losses }_{t}-\text { Gains }_{t}=B_{\text {cod }, t} T+L_{t}-B_{\text {cod }, t} P_{t}
$$

where Losses $_{t}$ represent biomass losses from the cod population at time $t$ due to all sources (i.e. metabolic loss, natural mortality and fisheries harvests), and Gains $_{t}$ represents the biomass gain of the cod population at time $t$ from somatic growth and reproduction.

There was very good correspondence between the net losses from the model and the total mortality rate calculated using RV data, except in 1991 (Fig. 9). If the year 1991 is not considered, the correlation coefficient between the variables is $r=0.65$.

\section{Somatic condition}

Condition of Atlantic cod was variable both in terms of space and time (Fig. 10). During the late 1970s and 1980s there was a spatial progression in fish condition, from better condition in northern areas (NAFO Division 2J) to poorer conditions in the south (NAFO Division 3L) (Fig. 10). As time progressed into the 1990s and 2000s, mean condition was lower than during the 1980s, and noticeably, the distributions of

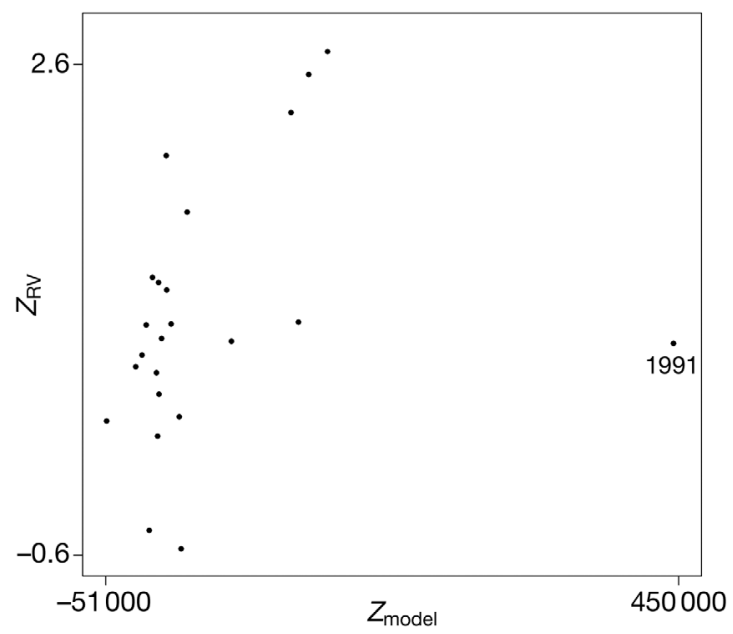

Fig. 9. Scatterplot of net losses from the most parsimonious model 'No seals $\left(\psi=2, q=1, I_{0}=80\right)$ ' $\left(Z_{\text {model }}\right)$ and total mortality rate of cod aged 4 to 6 yr calculated using data from the autumn RV surveys ( $Z_{\mathrm{RV}}$ ) (DFO 2011b) conditions curves were more leptokurtic. These responses were gradual in terms of space; the decrease in condition over time was more noticeable in the north (NAFO Division 2J), smaller in NAFO Division $3 \mathrm{~K}$ and less noticeable in the south of the study area (NAFO Division 3L) (Fig. 10). In addition, the median of the distribution during the late 1970s and 1980s was quite variable. During the 1990s and 2000s, all the condition distribution curves tended to be centered on a very similar median value (Fig. 10).

During most years, the mean somatic condition was below the value considered as excellent condition (i.e. $\bar{K}_{\mathrm{s}}<0.85$ ), with part of the distribution falling below the condition of starved fish (i.e. $K_{\mathrm{s}}<0.7$ ) (Fig. 10).

\section{DISCUSSION}

The northern cod stock that once sustained one of the largest fisheries worldwide collapsed in the early 1990s and has not recovered despite $20 \mathrm{yr}$ of highly reduced fishing. Intense fisheries exploitation was certainly an important factor in the collapse, although it is less clear if other factors also contributed to the collapse, and why the stock has not recovered despite low exploitation rates.

In this paper, we gauged the relative roles that fisheries removals, capelin availability and consumption by harp seals play in driving the dynamics of the stock through the implementation of a bioenergeticallometric cod biomass dynamic model. This framework allowed us to test multiple hypotheses on the roles of each of the drivers (Table 1) simultaneously and weight their relative empirical support (Tables 2 \& 3). We assumed the average weight of cod to be $1 \mathrm{~kg}$. It is expected that the average weight of cod changed during the period considered due to the truncation of the size structure of the population (Lilly et al. 2003). However, given that bioenergeticallometric models (Yodzis \& Innes 1992) consider body sizes that range from unicellular organisms to vertebrates, we would not expect relatively minor changes in mean weight to have a large impact on the model results. In fact, we fitted the models using 0.5 and $4 \mathrm{~kg}$ as average weights and found similar results (data not shown).

\section{Main drivers of northern cod dynamics}

The results of this modelling exercise indicate that during the period considered (1985 to 2007), the main drivers of the northern cod stock were capelin avail- 

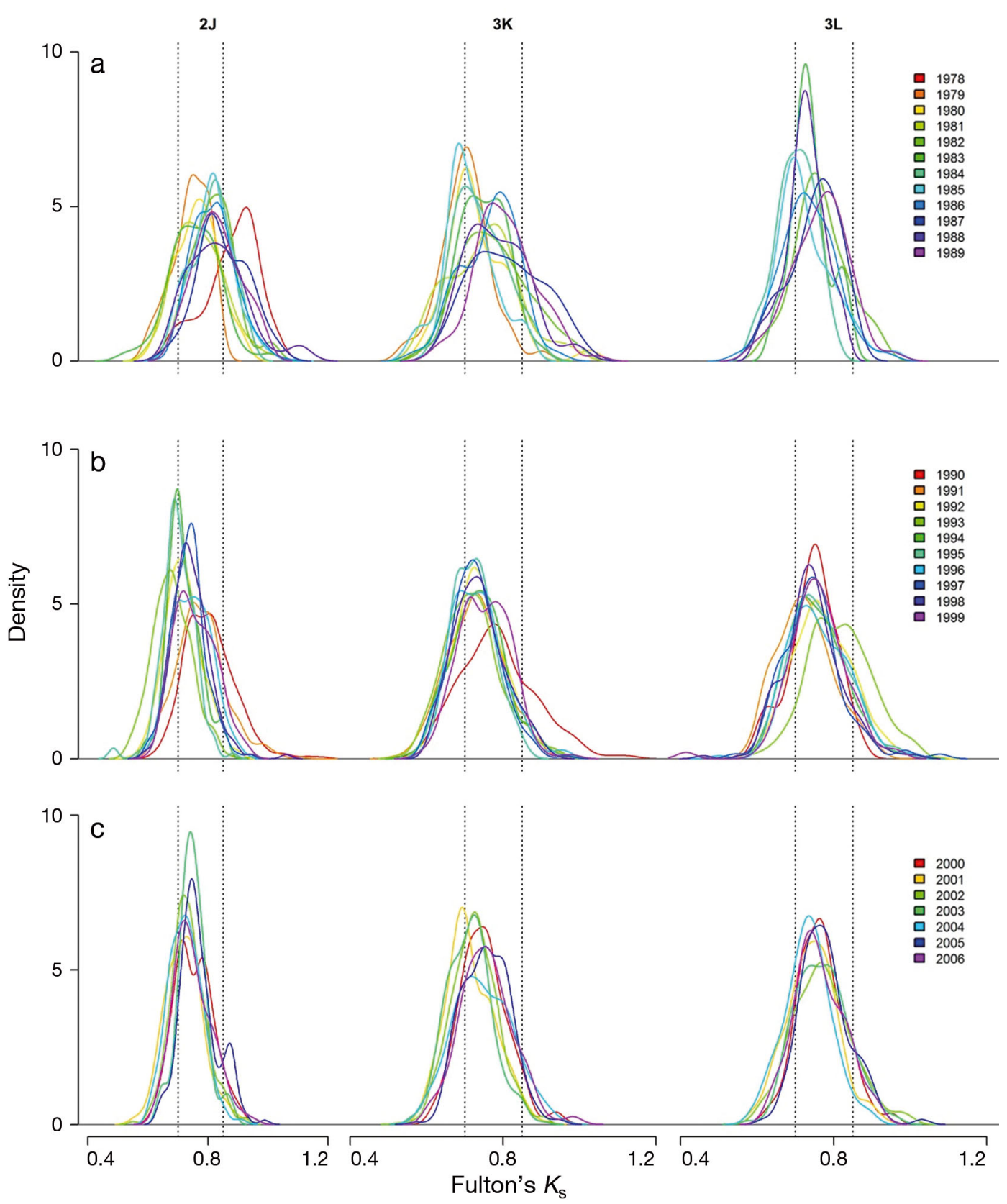

Fig. 10. Somatic condition of Atlantic cod (Fulton's $K_{\mathrm{s}}$ ) during spring. (a) Represents late 1970s and 1980s, (b) the 1990s, and (c) the 2000s. 2J, 3K and 3L indicate Northwest Atlantic Fisheries Organization (NAFO) Divisions (see Fig. 1); vertical lines indicate values of $K_{\mathrm{s}}$ for excellent (0.85) and starved (0.7) condition

ability and fisheries removals, and that consumption by harp seals was not a major forcer of the cod dynamics. The interplay between the 2 drivers could not, however, be fully resolved. This was likely due to missing capelin surveys during the 1990s (1993 to $1995,1997,1998)$ and 2006. Looking to balance the effects of fisheries and capelin, we found that our most parsimonious model was the 'No seals' model with a half saturation rate $\left(I_{0}\right)$ of $80 \mathrm{kt}$.
The good correspondence between quantities predicted from our most parsimonious model and 3 different independent data sources suggests that the model captures the most significant drivers of the northern cod stock biomass dynamics. The comparisons we carried to validate the model were (1) forecasted biomass levels for 2008 to 2010 vs. biomass estimated by the RV surveys (Fig. 8), (2) hindcasted biomass levels for 1969 to 1984 vs. an accepted view 
of the trajectory of the stock's biomass, the output of the missing fish SPA (Shelton \& Lilly 2000, Smedbol et al. 2002) (Fig. 8), and (3) a proxy for annual mortality rate from our model vs. mortality rates estimated from the RV survey data (DFO 2011b) (Fig. 9).

\section{Fisheries harvest as a driver}

As expected, our analyses indicated that fisheries harvest has been an important driver of the northern cod stock's dynamics during the period considered (1985 to 2007). The mechanisms through which fishing affects the dynamics of northern cod have been studied extensively (Hutchings \& Myers 1994, Hutchings 1996, Myers et al. 1996, Myers et al. 1997, Rose 2004, Shelton et al. 2006, Lilly et al. 2008, Hilborn \& Litzinger 2009). Our study reinforces the notion that fisheries harvest was an important factor in the collapse of Atlantic cod off Newfoundland during the early 1990s.

\section{Capelin availability as a driver}

The role of capelin availability in driving the dynamics of the northern cod stock is likely linked to individual energy allocation. In this study, we used capelin availability as a proxy for the quality of the prey field; high abundances of capelin represent a good quality and low abundances a poor quality prey field. The rationale for this is that capelin is the most energetically dense of cod's prey in the Northwest Atlantic (Lawson et al. 1998b). We therefore expected that the changes in capelin biology and ecology that took place during the 1990s, and most importantly its severe abundance decline, must have represented a serious burden. Northern cod's diet composition changed from a heavy reliance on capelin during the 1980s and early 1990s to a reliance more on Pandalus shrimp, prey with a much lower energy density, during the late 1990s and 2000s; this shift was more marked in the northern regions (Dawe et al. 2012, DFO 2012, Krumsick \& Rose 2012). We used Lambert's $(2011,2012)$ simple linear regression relating Atlantic cod's somatic condition during January to somatic condition during May in the northern Gulf of St. Lawrence to convert fall to spring somatic condition (when it is at its minimum), which allowed us to compare spring condition to threshold values found in starvation and feeding experiments (Lambert \& Dutil 1997). This rescaling only lowers the condition of each fish considered, but does not change the shape of the condition curves obtained. Thus, even in the case that Lambert's $(2011,2012)$ relationship or Lambert \& Dutil's (1997) benchmark values did not hold for cod in NAFO Divisions 2J3KL, conclusions drawn from the shapes of the condition curves would still stand.

All organisms face a trade-off between reproduction, growth and survival. These trade-offs are mediated through the allocation of energy toward stores or growth; stored energy determines fecundity if reproduction occurs and survival in the event of low prey availability (Jørgensen et al. 2006). The growth rate of northern cod is influenced by both food availability and environmental temperature (Krohn et al. 1997, Brander 2007); thus, cod's ability to utilize growth as currency in this trade-off is likely limited. On the other hand, iteroparous fish may skip spawning, favoring growth or survival in any given year. Therefore, if female cod in poor condition invest their energy in reproduction, they do so at the cost of increasing their risk of mortality (Lambert \& Dutil 2000). The most commonly reported cause of skipped spawning in fish is poor nutrition (Rideout et al. 2005). The distribution of the condition factor over time suggests a decrease in somatic condition during the 1990s and early 2000s in NAFO Division 2J, and to some extent in Division 3K (Fig. 10). This is consistent with reports of low growth, somatic condition, liver index and age-at-maturity associated with diets dominated by Pandalus shrimp (Sherwood et al. 2007, Krumsick \& Rose 2012). The distribution of the somatic condition curves was more leptokurtic as time progressed (Fig. 10). In probabilistic terms, this would mean that there was a larger chance of finding individuals in poor condition during the 1990s and early 2000 s than during the 1980s. In addition, the medians of the condition factor distributions showed a higher inter-annual variability during the 1970 s and 1980s (Fig. 10); thus, the effects of a large proportion of fish being in poor condition in any given year would be buffered by smaller proportions in other years. This 'buffer' effect was lost during the 1990s and early 2000s when the median condition of fish was poor for several consecutive years. In this context, skipping spawning during a bad year may not have been a successful strategy. The frequency of skipped spawning in the offshore component of the stock was very low during the period between 1978 and 2004 (in Division 2J: 0.33\%, 3K: 3.45\%, 3L: $8.11 \%$ ), with no apparent trend in the proportion of fish that skipped spawning (Rideout et al. 2006). In contrast, a large proportion of potential female spawners in Smith Sound supressed reproduction between 
1999 and 2004 (Rideout \& Rose 2006). This large inshore aggregation fared well in terms of spawning biomass during the last half of the 1990s and first half of the 2000s (Rideout \& Rose 2006). Thus, cod in the inshore component apparently invested energy toward survival, forgoing reproduction, while cod in the offshore component may have been investing its compromised energy reserves toward reproduction in detriment of survival. The effects of a fish in poor condition spawning will not only be felt in terms of its own survival, but also in terms of the quantity and quality of the eggs produced (affecting the probability of larvae surviving to maturity). Consistent with this idea, there have been reports of reduced average productivity and cumulative individual egg production per recruit of the northern cod stock (Shelton et al. 2006, Fudge \& Rose 2008).

Lilly et al. (2003) reported that no problems had been identified in the offshore component of the stock during the regular autumn research surveys. However, these authors only analyzed trends in mean condition, and therefore would not have been able to detect differences in distribution of condition over time. Notwithstanding, they report concern that there might not be sufficient capelin available to restore the northern cod stock to its former level of abundance.

Our interpretation is that although cod can survive without capelin, having a lipid rich diet (such as that provided by capelin) gives cod the edge needed, not only to survive in the harsh environment of the Northwest Atlantic, but also to produce strong progeny in terms of both numbers and quality.

\section{Harp seal consumption as a driver}

Notably, the significant drivers of the stock do not include consumption by harp seals. In this study, we included a variety of plausible shapes that the trajectory of cod consumption by seals could take, as a result of 3 different descriptions of the diet utilized to estimate consumption levels. In addition, we allowed the consumptions to scale up or down during model fitting. We therefore addressed uncertainty in terms of the form of seal consumption and in terms of the magnitude of the consumption. Thus, the evidence leads us to reject the hypothesis that seal predation has been an important driver of the cod stock.

Nonetheless, one might wonder if the residual variation not explained by our models could be explained by harp seal consumption. As fisheries harvest has an unquestionable role on the dynamics of cod, we present the residuals from the 'Only fisheries' models (both likelihoods), the 'No seals' models (both likelihoods) and from our most parsimonious model 'No seals $\left(\psi=2, I_{0}=80\right)^{\prime}$ in Fig. 11. The most conspicuous feature of the residuals in the arithmetic scale is that
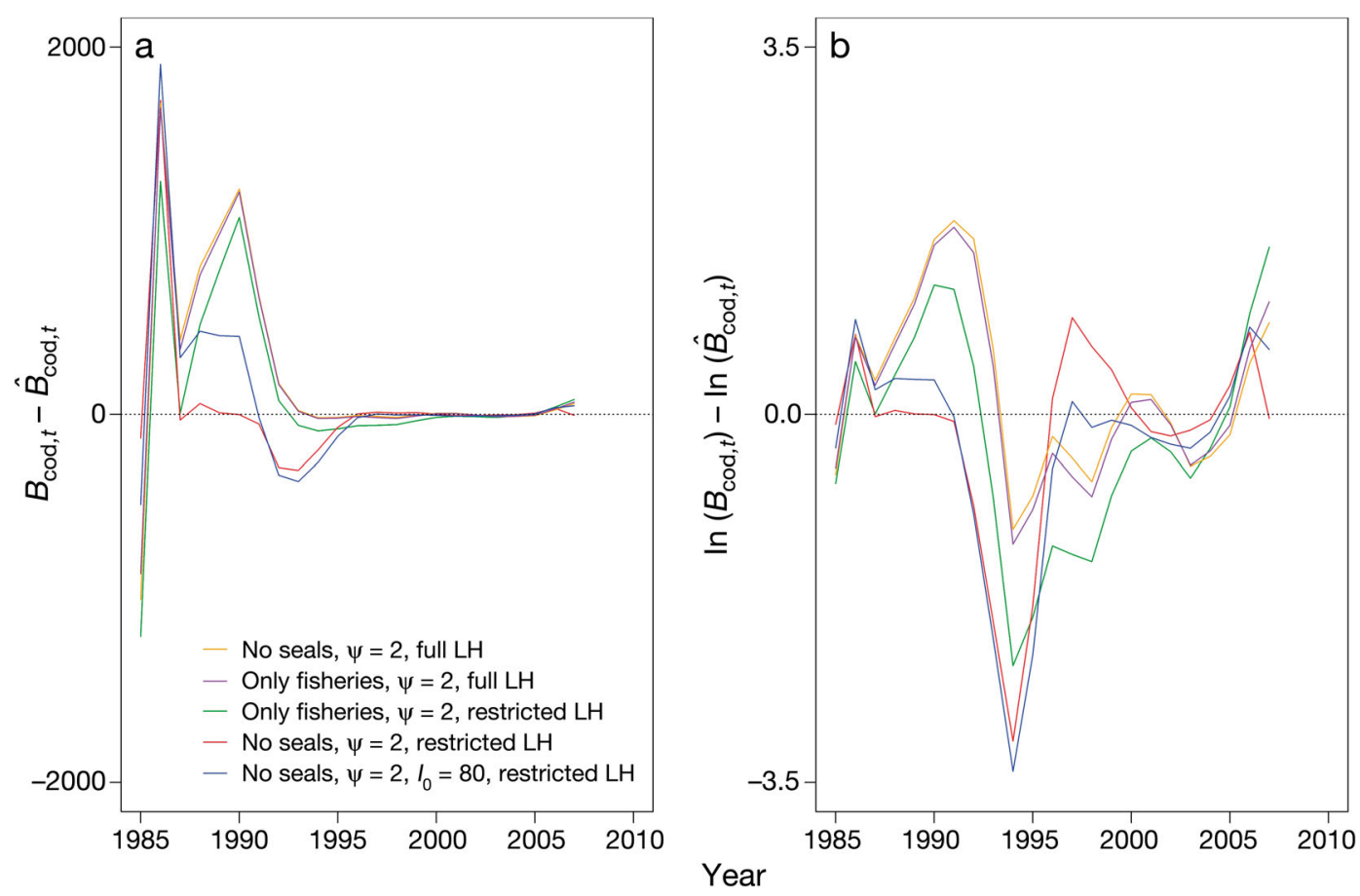

Fig. 11. Residual from the models 'Only fisheries', 'No seals', and the most parsimonious model 'No seals $\left(\psi=2, q=1, I_{0}=80\right)$ '. Residuals were calculated based on the (a) arithmetic, and (b) logarithmic scales. LH: likelihood 
they show large fluctuations in the pre-collapse period, and afterwards the variation is overshadowed because of the large differences in magnitude of the biomass estimates. When the residuals are examined in the logarithmic scale, a quasi-sinusoidal pattern clearly emerges, reaching the lowest point in 1994, particularly for the models that were fitted considering the restricted likelihood. There is no plausible way in which to reconcile this pattern with cod consumption by harp seals. Plausible drivers that could account for this pattern would be the effect of other food items or an environmental forcer such as temperature. We found good correspondence between the residuals of the best 'No seals $(\psi=2)$ ' and the most parsimonious 'No seals $\left(\psi=2, I_{0}=80\right)$ ' models and the mean annual bottom (depth $\leq 150 \mathrm{~m}$ ) temperature at Stn 27 (Fig. 12), although there seems to be an offset in this relationship during the 1980s compared to subsequent years. Thus, our modelling exercise suggests that environmental conditions may also influence the dynamics of the northern cod. Drinkwater (2002) provided evidence that environmental variability plays a role on the dynamics of the northern cod stock via its effects on individual growth rates, displacements of the stock, and likely lower recruitment, although these effects have not yet been integrated into a dynamic model. This warrants further study into the mechanistic links between temperature and the rate of change of the northern cod stock biomass.

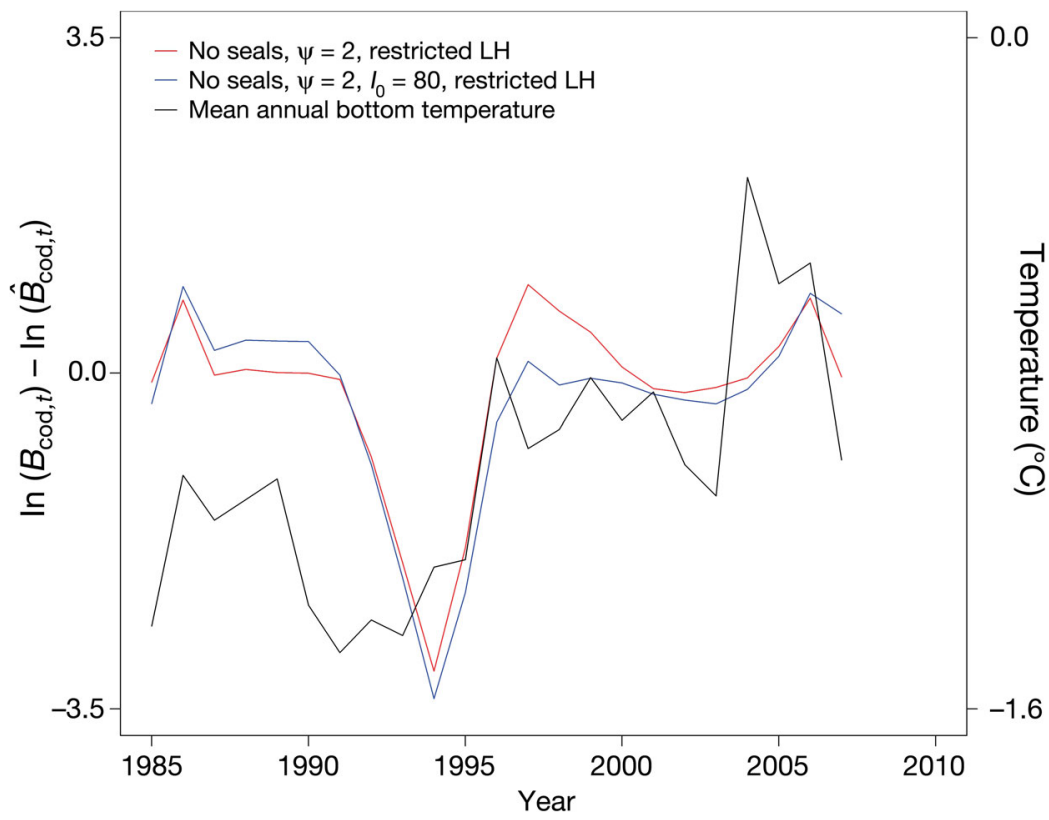

Fig. 12. Mean annual bottom (depth $\leq 150 \mathrm{~m}$ ) temperature at Stn 27 and the residuals from the best model (restricted likelihood set): 'No seals $(\psi=2)$ 'and the most parsimonious model 'No seals $\left(\psi=2, q=1, I_{0}=80\right)$ '
Bundy (2001) explored whether the relative effects of fishing and predation could account for the collapse of the northern cod and other groundfish stocks. This author modeled 31 functional components of the Newfoundland-Labrador Shelf marine ecosystem and found support for the hypothesis that the recovery of the northern cod was being retarded by harp seal predation. However, at the time Bundy (2001) conducted her study, capelin biomass estimates were derived from an assortment of sources that included bottom trawl surveys, commercial catch data, an aerial survey and data on capelin egg deposition on beaches, and the view at the time was that the stock biomass had been steadily increasing since 1980 through to 1996 (Nakashima \& Winters 1997). After the publication of Bundy's (2001) study, a comparative analysis concluded that acoustic integration supported by directed trawling is a more reliable approach than traditional bottom trawl surveys for producing indices of capelin abundance (O'Driscoll et al. 2002). Applying this later methodology, the currently accepted view is that the capelin stock suffered a drastic decline in 1991 from which it has not yet recovered (Fig. 2C, DFO 2010). If today's perspective on capelin status and trend during the 1990s were to be considered, it would be possible that simulations like the ones carried out by Bundy (2001) may render different outcomes. This possibility suggests that an updated multispecies modelling study for the Newfoundland-Labrador marine ecosystem would be of both scientific and management value.

\section{Predator pit effect}

Shelton \& Healey (1999) suggest that the northern cod stock may have depensatory dynamics caused by consumption by harp seals (i.e. a 'predator pit'). A population's dynamics are depensatory if the per-capita rate of growth decreases as the density decreases to low levels (Liermann \& Hilborn 2001). Several mechanisms can lead to depensation: reduced probability of fertilization, impaired group dynamics, conditioning of the environment and predator saturation (Liermann \& Hilborn 2001). The concepts of depensation and predator pit are illustrated in Fig. 13a: the part of the growth rate curve between the minimum and unstable equilibrium 

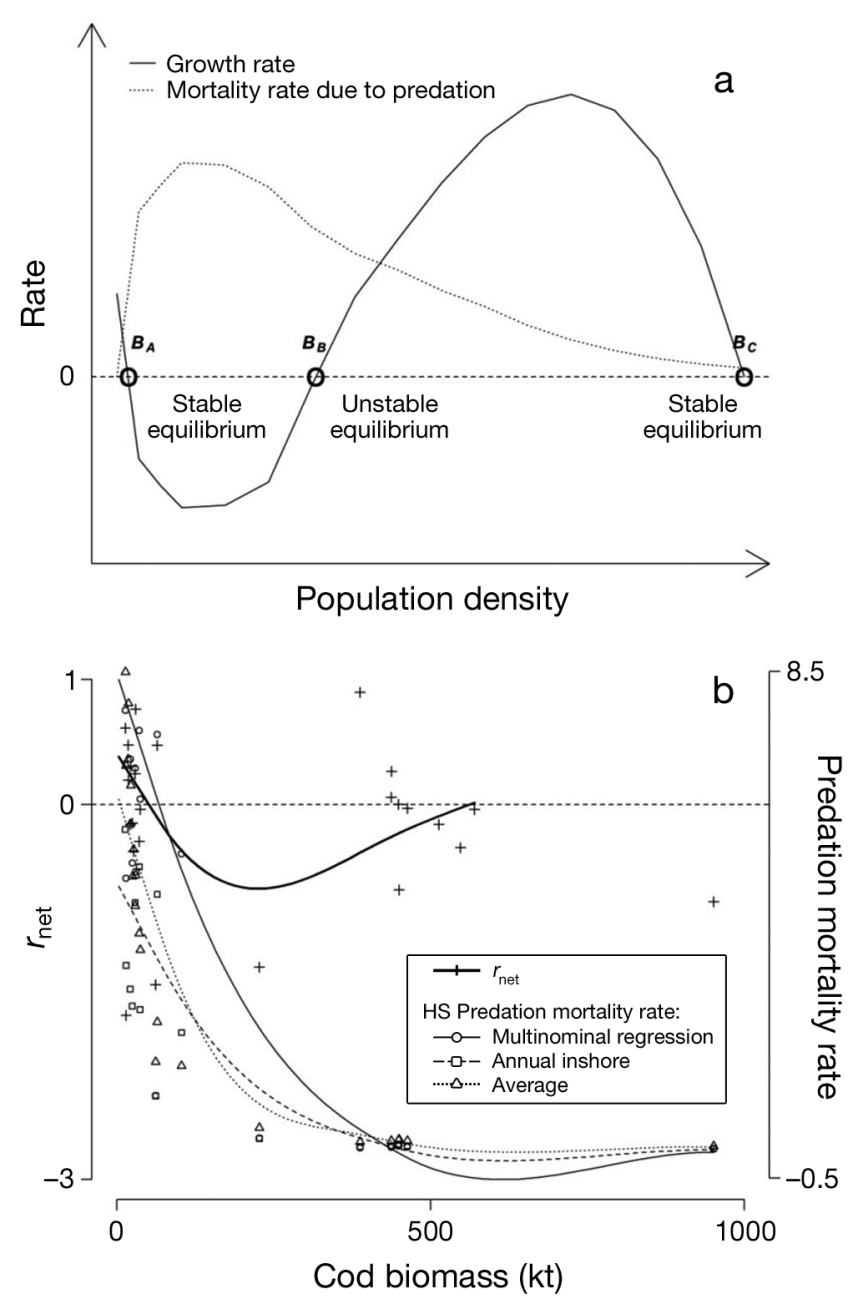

Fig. 13. Growth rate and predation mortality as a function of population density. (a) Per-capita growth rate of a population that exhibits depensation and shape of the mortality rate due to predation needed to cause a predator pit. $B_{A}, B_{B}$ and $B_{C}$ are equilibrium biomasses. The part of the curve between the minimum growth rate and $B_{B}$ is considered depensatory. If depensatory dynamics are caused by predation mortality, biomasses lower than $B_{B}$ represent the predator pit. (b) Net rate of increase $\left(r_{\text {net }}\right)$ and cod mortality rates due to harp seal (HS) predation calculated using the multinomial regression, yearly inshore, and classic diets

$\left(B_{B}\right)$ is considered depensatory. If the biomass falls below $B_{B}$, it will be driven to even lower levels and eventually to the lower stable equilibrium $\left(B_{A}\right)$. If these dynamics are caused by predation mortality, biomasses lower than $B_{B}$ represent the predator pit. A predator pit occurs when the predation probability decreases above and below an intermediate level of prey abundance (Bakun 2006; the concept is identical if we replace abundance by biomass) (Fig. 13a). The predation probability decreases above an intermediate level of prey biomass due to predator satura- tion, and thus if the prey biomass exceeds this critical point it can break out from the pit. The probability of predation decreases below a critical level because of prey 'refuges' at low density.

Considering this, what is the evidence that the dynamics of northern cod are depensatory? To assess this question, we calculated the net rate of increase following Sinclair et al. (1998) using the survey biomass instead of numbers as follows: $r_{\text {net }}=\ln \left(B_{\mathrm{cod}, t+1} /\right.$ $\left.B_{\mathrm{cod}, t}\right)$, and present the point estimates with a fitted loess curve in order to visualize trends in the data (we excluded years influenced by the anomalously high biomass recorded in 1986) (Fig. 13b). The shape of the resulting curve suggests that the dynamics are depensatory and that the magnitude of the unstable equilibrium $B_{B}$ is $\sim 450 \mathrm{kt}$, the level observed throughout the 1980s. Is depensation caused by harp seal predation mortality, i.e. is cod in a harp seal predator pit? We calculated the mortality rate due to predation by harp seals as the ratio of the consumption by harp seals in a given year to the biomass of cod in that year, and present the point estimates with fitted loess curves. The shape of the mortality rate predation curves are best described as exponentially decreasing (Fig. 13b), and thus bear no resemblance with the shape of the mortality rates needed to create a predator pit. As a consequence, we agree with Shelton \& Healey (1999) that the northern cod may have depensatory dynamics. However, we disagree as to the mechanisms that may prompt these dynamics. The evidence suggests that the northern cod is not in a predator pit. Nonetheless, it seems that the biomass of northern cod would have to be pushed beyond roughly $\sim 500 \mathrm{kt}$ for it to break out from the depensatory dynamics. It may take one or several good year-classes to produce this level of recruitment. However, year-class strength in the offshore has been very poor since 1990 (DFO 2011b). The issue of depensatory dynamics in northern cod warrants further investigation.

\section{CONCLUSIONS}

In this paper, we provided evidence that the biomass dynamics of the northern cod stock has been driven by the fishery and the availability of lipid-rich capelin. Taking into account that capelin seems to be environmentally driven (Buren et al. 2014), our findings here reinforce the notion that bottom-up regulation is important in this system through multiple trophic levels, including the possibility that the cod's dynamics may, at least in part, be explained by phys- 
ical drivers. Our study clearly supports the view that system-wide production and the regulatory mechanisms that forage species play in the ecosystem are fundamental to the development of ecosystem-based fisheries management approaches.

Acknowledgements. This work was supported by the DFO Ecosystem Research Initiative (ERI) in the Newfoundland and Labrador Region, the NEREUS program (PI: M.K.A) and scholarships (Memorial University of Newfoundland) to A.D.B. We thank George Lilly, John Brattey and Fran Mowbray for sharing their data and comments. We also thank all staff at the Northwest Atlantic Fisheries Centre's Marine Mammal, Groundfish, Pelagics and Ecological Sciences sections who provided support and collected the data used in this study. The Canada-Newfoundland Operational Ocean Forecasting System (C-NOOFS) Team and Andry Ratsimandresy helped with computing. Joanne Morgan, Peter Shelton, Hugues Benoît and Bill Montevecchi provided reviews, suggestions and/or comments that improved the quality of the manuscript.

\section{LITERATURE CITED}

Anderson DR (2008) Model based inference in the life sciences: a primer on evidence. Springer, New York, NY

Bakun A (2006) Wasp-waist populations and marine ecosystem dynamics: navigating the "predator pit" topographies. Prog Oceanogr 68:271-288

Benoît HP, Swain DP, Bowen WD, Breed GA, Hammill MO, Harvey V (2011) Evaluating the potential for grey seal predation to explain elevated natural mortality in three fish species in the southern Gulf of St. Lawrence. Mar Ecol Prog Ser 442:149-167

Bowen WD (1997) Role of marine mammals in aquatic ecosystems. Mar Ecol Prog Ser 158:267-274

Brander KM (2007) The role of growth changes in the decline and recovery of North Atlantic cod stocks since 1970. ICES J Mar Sci 64:211-217

Brattey J, Cadigan NG, Dwyer KS, Healey BP and others (2011) Assessment of the cod (Gadus morhua) stock in NAFO Divisions 2J+3KL in 2010. Can Sci Advis Sec Res Doc 2010/103

Bundy A (2001) Fishing on ecosystems: the interplay of fishing and predation in Newfoundland-Labrador. Can J Fish Aquat Sci 58:1153-1167

Buren AD, Koen-Alonso M, Pepin P, Mowbray F and others (2014) Bottom-up regulation of capelin, a keystone forage species. PLoS ONE 9:e87589

Burnham KP, Anderson DR (2002) Model selection and multimodel inference: a practical information-theoretic approach. Springer, New York, NY

Carscadden JE, Frank KT (2002) Temporal variability in the condition factors of Newfoundland capelin (Mallotus villosus) during the past two decades. ICES J Mar Sci 59: 950-958

Carscadden JE, Nakashima BS (1997) Abundance and changes in distribution, biology and behavior of capelin in response to cooler water of the 1990s. In: Forage fishes in marine ecosystems. Alaska Sea Grant College Program Rep AK-SG-97-01, University of Alaska Fairbanks, AK, p 457-468
Chassot E, Duplisea D, Hammill M, Caskenette A, Bousquet N, Lambert Y, Stenson G (2009) Role of predation by harp seals Pagophilus groenlandicus in the collapse and non-recovery of northern Gulf of St. Lawrence cod Gadus morhua. Mar Ecol Prog Ser 379:279-297

Dawe E, Koen-Alonso M, Chabot D, Stansbury D, Mullowney D (2012) Trophic interactions between key predatory fishes and crustaceans: comparison of two Northwest Atlantic systems during a period of ecosystem change. Mar Ecol Prog Ser 469:233-248

DFO (2003a) Northern (2J+3KL) cod stock status update. Can Sci Advis Sec Status Rep 2003/018

DFO (2003b) Proceedings of the zonal assessment meeting: Atlantic cod. Can Sci Advis Sec Proc Ser 2003/021

DFO (2008a) Proceedings of the national workshop on the impacts of seals on fish populations in eastern Canada (Part 1). Can Sci Advis Sec Proc Ser 2008/021

DFO (2008b) Stock assessment of northern (2J3KL) cod in 2008. Can Sci Advis Sec Advis Rep 2008/034

DFO (2009) Proceedings of the national workshop on the impacts of seals on fish populations in eastern Canada (Part 2). Can Sci Advis Sec Proc Ser 2009/020

DFO (2010) Assessment of capelin in SA2+Div. 3KL in 2010. Can Sci Advis Sec Sci Advis Rep 2010/090

DFO (2011a) Impacts of grey seals on fish populations in Eastern Canada. Can Sci Advis Sec Advis Rep 2010/071

DFO (2011b) Stock assessment of northern (2J3KL) cod in 2011. Can Sci Advis Sec Sci Advis Rep 2011/041

DFO (2012) Results and recommendations from the Ecosystem Research Initiative - Newfoundland and Labrador's expanded research on ecosystem relevant but undersurveyed splicers. Can Sci Advis Sec Sci Advis Rep 2012/ 058

DFO (2013) Assessment of capelin in SA2+Div. 3KL in 2013. Can Sci Advis Sec Sci Advis Rep 2013/011

Drinkwater KF (2002) A review of the role of climate variability in the decline of northern cod. In: McGinn NA (ed) Fisheries in a changing climate. Am Fish Soc Symp 32: 113-129

Flaaten O (1988) The economics of multispecies harvesting. Theory and application to the Barents Sea fishery. Springer-Verlag, Berlin

Frank KT, Carscadden JE, Simon JE (1996) Recent excursions of capelin (Mallotus villosus) to the Scotian Shelf and Flemish Cap during anomalous hydrographic conditions. Can J Fish Aquat Sci 53:1473-1486

FRCC (2011) Towards recovered and sustainable groundfish fisheries in Eastern Canada. Fisheries Resource Conservation Council, Ottawa

Fudge SB, Rose GA (2008) Life history co-variation in a fishery depleted Atlantic cod stock. Fish Res 92:107-113

Goldsworthy SD, Bulman C, He X, Larcombe J, Littnan C (2003) Trophic interactions between marine mammals and Australian fisheries: an ecosystem approach. In: Gales N, Hindell M, Kirkwood R (eds) Marine mammals. Fisheries, tourism and management issues. CSIRO Publishing, Collingwood

Halliday RG, Pinhorn AT (2009) The roles of fishing and environmental change in the decline of Northwest Atlantic groundfish populations in the early 1990s. Fish Res 97:163-182

Hammill MO, Stenson GB (2011) Modelling grey seal abundance in Canadian waters. Can Sci Advis Sec Sci Res Doc 2011/014 
Hammill MO, Stenson GB, Doniol-Valcroze T, Mosnier A (2013) Estimating carrying capacity and population trends of Northwest Atlantic harp seals, 1952-2012. Can Sci Advis Sec Sci Res Doc 2012/148

> Harwood J (1992) Assessing the competitive effects of marine mammal predation on commercial fisheries. S Afr J Mar Sci 12:689-693

> Hilborn R, Litzinger E (2009) Causes of decline and potential for recovery of Atlantic cod populations. The Open Fish Science Journal 2:32-38

Hilborn R, Mangel M (1997) The ecological detective: confronting models with data. Princeton University Press, Princeton, NJ

> Hutchings JA (1996) Spatial and temporal variation in the density of northern cod and a review of hypotheses for the stock's collapse. Can J Fish Aquat Sci 53:943-962

> Hutchings JA, Myers RA (1994) What can be learned from the collapse of a renewable resource? Atlantic cod, Gadus morhua, of Newfoundland and Labrador. Can J Fish Aquat Sci 51:2126-2146

IMSL (2006) IMSL MATH/LIBRARY user's manual, version 6.0. Rogue Wave Software, Houston, TX

> Jørgensen C, Ernande B, Fiksen Ø, Dieckmann U (2006) The logic of skipped spawning in fish. Can J Fish Aquat Sci 63:200-211

Koen-Alonso M, Buren AD, Stenson GB (2009) A multinomial regression approach to reconstruct diet composition. In: Bowen WD, Hammill MO, Koen-Alonso M, Stenson GB, Swain DP, Trzcinski K (eds) Proceedings of the national workshop on the impacts of seals on fish populations in eastern Canada (Part 2). Can Sci Advis Sec Proc Ser 2009/20, p 24-29

- Krohn M, Reidy S, Kerr S (1997) Bioenergetic analysis of the effects of temperature and prey availability on growth and condition of northern cod (Gadus morhua). Can J Fish Aquat Sci 54(Suppl 1):113-121

Krumsick KJ, Rose GA (2012) Atlantic cod (Gadus morhua) feed during spawning off Newfoundland and Labrador. ICES J Mar Sci 69:1701-1709

> Lambert Y (2011) Environmental and fishing limitations to the rebuilding of the northern Gulf of St. Lawrence cod stock (Gadus morhua). Can J Fish Aquat Sci 68: 618-631

Lambert Y (2012) Erratum: environmental and fishing limitations to the rebuilding of the northern Gulf of St. Lawrence cod stock (Gadus morhua). Can J Fish Aquat Sci 69:612

Lambert Y, Dutil JD (1997) Condition and energy reserves of Atlantic cod (Gadus morhua) during the collapse of the northern Gulf of St. Lawrence stock. Can J Fish Aquat Sci 54:2388-2400

Lambert Y, Dutil JD (2000) Energetic consequences of reproduction in Atlantic cod (Gadus morhua) in relation to spawning level of somatic energy reserves. Can J Fish Aquat Sci 57:815-825

Lavigne DM (1996) Ecological interactions between marine mammals, commercial fisheries and their prey: unravelling the tangled web. In: Montevecchi WA (ed) Studies of high-latitude seabirds. 4. Trophic relationships and energetics of endotherms in cold ocean systems. Occas Pap Can Wildl Serv 91:59-71

Lawson JW, Anderson JT, Dalley EL, Stenson GB (1998a) Selective foraging by harp seals Phoca groenlandica in nearshore and offshore waters of Newfoundland, 1993 and 1994. Mar Ecol Prog Ser 163:1-10
Lawson JW, Magalhães AM, Miller EH (1998b) Important prey species of marine vertebrate predators in the northwest Atlantic: proximate composition and energy density. Mar Ecol Prog Ser 164:13-20

> Le Cren ED (1951) The length-weight relationship and seasonal cycle in gonad weight and condition in the perch (Perca fluviatilis). J Anim Ecol 20:201-219

Liermann M, Hilborn R (2001) Depensation: evidence, models and implications. Fish Fish 2:33-58

Lilly GR (1987) Interactions between Atlantic cod (Gadus morhua) and capelin (Mallotus villosus) off Labrador and eastern Newfoundland: a review. Can Tech Rep Fish Aquat Sci 1567:1-37

Lilly GR (1991) Interannual variability in predation by cod (Gadus morhua) on capelin (Mallotus villosus) and other prey off southern Labrador and northeastern Newfoundland. ICES Mar Sci Symp 193:133-146

Lilly GR, Shelton PA, Brattey J, Cadigan NG and others (2003) An assessment of the cod stock in NAFO Divisions $2 \mathrm{~J}+3 \mathrm{KL}$ in February 2003. Can Sci Advis Sec Res Doc 2003/023

Lilly GR, Wieland K, Rothschild BJ, Sundby S and others (2008) Decline and recovery of Atlantic cod (Gadus morhua) stocks throughout the North Atlantic. In: Kruse GH, Drinkwater KF, Ianelli JN, Link JS, Stram DL, Wespestad V, Woodby D (eds) Resiliency of gadid stocks to fishing and climate change. Alaska Sea Grant College Program Rep AK-SG-08-01, University of Alaska Fairbanks, AK, p 39-66

> May RM, Beddington JR, Clark CW, Holt SJ, Laws RM (1979) Management of multispecies fisheries. Science 205:267-277

McLaren I, Brault S, Harwood J, Vardy D (2001) Report of the Eminent Panel on Seal Management. Fisheries and Oceans Canada, Ottawa. http://publications.gc.ca/ collections/Collection/Fs23-405-2001E.pdf

Mello LGS, Rose GA (2005) Seasonal cycles in weight and condition in Atlantic cod (Gadus morhua L.) in relation to fisheries. ICES J Mar Sci 62:1006-1015

Miller DS (1997) Results from an acoustic survey for capelin (Mallotus villosus) in NAFO Divisions 3KL in the spring of 1996. In: Capelin in SA2 + Div 3KL Can Stock Assess Sec Res Doc 97/29, p 84-90

Mowbray F (2002) Changes in the vertical distribution of capelin (Mallotus villosus) off Newfoundland. ICES J Mar Sci 59:942-949

Mowbray F (2012) Some results from spring acoustic surveys for capelin (Mallotus villosus) in NAFO Division 3L between 1982 and 2010. Can Sci Advis Sec Res Doc 2012/143

> Myers RA, Hutchings JA, Barrowman NJ (1996) Hypotheses for the decline of cod in the North Atlantic. Mar Ecol Prog Ser 138:293-308

Myers RA, Hutchings JA, Barrowman NJ (1997) Why do fish stocks collapse? The example of cod in Atlantic Canada. Ecol Appl 7:91-106

Nakashima BS, Wheeler JP (2002) Capelin (Mallotus villosus) spawning behaviour in Newfoundland waters - the interaction between beach and demersal spawning. ICES J Mar Sci 59:909-916

Nakashima BS, Winters GH (1997) Multiplicative trends of biomass, cohort abundance and recruitment of capelin, Mallotus villosus. In: Capelin in SA2 + Div 3KL. Can Stock Assess Sec Res Doc 97/29, p 168-188

Northridge SP (1991) An updated world review of inter- 
actions between marine mammals and fisheries. FAO Fish Tech Pap No. 251 (Suppl 1). FAO, Rome

O'Driscoll RL, Rose GA, Anderson JT (2002) Counting capelin: a comparison of acoustic density and trawl catchability. ICES J Mar Sci 59:1062-1071

Punt AE, Butterworth DS (1995) The effects of future consumption by the Cape fur seal on catch rates of the Cape hakes. 4. Modelling the biological interactions between Cape fur seals Arctocephalus pusillus pusillus and the Cape hakes Merluccius capensis and M. paradoxus. S Afr J Mar Sci 16:255-285

- Rideout RM, Morgan MJ (2010) Relationships between maternal body size, condition and potential fecundity of four north-west Atlantic demersal fishes. J Fish Biol 76: 1379-1395

Rideout RM, Rose GA (2006) Suppression of reproduction in Atlantic cod Gadus morhua. Mar Ecol Prog Ser 320: 267-277

Rideout RM, Rose GA, Burton MPM (2005) Skipped spawning in female iteroparous fishes. Fish Fish 6:50-72

Rideout RM, Morgan MJ, Lilly GR (2006) Variation in the frequency of skipped spawning in Atlantic cod (Gadus morhua) off Newfoundland and Labrador. ICES J Mar Sci 63:1101-1110

Rose GA (2004) Reconciling overfishing and climate change with stock dynamics of Atlantic cod (Gadus morhua) over 500 years. Can J Fish Aquat Sci 61:1553-1557

> Rose GA, O'Driscoll RL (2002) Capelin are good for cod: Can the northern stock rebuild without them? ICES J Mar Sci 59:1018-1026

Ruzicka JJ, Steele JH, Ballerini T, Gaichas SK, Ainley DG (2013) Dividing up the pie: whales, fish, and humans as competitors. Prog Oceanogr 116:207-219

Shelton PA, Healey BP (1999) Should depensation be dismissed as a possible explanation for the lack of recovery of the northern cod (Gadus morhua) stock? Can J Fish Aquat Sci 56:1521-1524

Shelton PA, Lilly GR (2000) Interpreting the collapse of the northern cod stock from survey and catch data. Can J Fish Aquat Sci 57:2230-2239

- Shelton PA, Warren WG, Stenson GB (1997) Quantifying some of the major sources of uncertainty associated with estimates of harp seal prey consumption. Part II: Uncertainty in consumption estimates associated with population size, residency, energy requirement and diet. J Northwest Atl Fish Sci 22:303-315

Shelton PA, Sinclair AF, Chouinard GA, Mohn R, Duplisea DE (2006) Fishing under low productivity conditions is further delaying recovery of Northwest Atlantic cod (Gadus morhua). Can J Fish Aquat Sci 63:235-238

Sherwood GD, Rideout RM, Fudge SB, Rose GA (2007) Influence of diet on growth, condition and reproductive capacity in Newfoundland and Labrador cod (Gadus morhua): insights from stable carbon isotopes $\left(\delta^{13} \mathrm{C}\right)$. Deep-Sea Res II 54:2794-2809

Editorial responsibility: Peter Corkeron, Woods Hole, Massachusetts, USA
Siarry P, Berthiau G, Durbin F, Haussy J (1997) Enhanced simulated annealing for globally minimizing functions of many-continuous variables. ACM Trans Math Softw 23: 209-228

> Sinclair ARE, Pech RP, Dickman CR, Hik D, Mahon P, Newsome AE (1998) Predicting effects of predation on conservation of endangered prey. Conserv Biol 12:564-575

Smedbol RK, Shelton PA, Swain DP, Fréchet A, Chouinard GA (2002) Review of population structure, distribution and abundance of cod (Gadus morhua) in Atlantic Canada in a species-at-risk context. Can Sci Advis Sec Res Doc 2002/082

Stenson GB (2012) Estimating consumption of prey by harp seals (Pagophilus groenlandicus) in NAFO Divisions 2J3KL. Can Sci Advis Sec Res Doc 2012/156

Stenson GB, Sjare B (1997) Seasonal distribution of harp seals, Phoca groenlandica, in the Northwest Atlantic. ICES CM 1997/CC:10

Swain DP, Benoît HP, Hammill M, McClelland G, Aubry É (2011) Alternative hypotheses for causes of the elevated mortality of cod (Gadus morhua) in the southern Gulf of St. Lawrence: the weight of evidence. Can Sci Advis Sec Res Doc 2011/036

Thomas L, Hammill MO, Bowen WD (2011) Estimated size of the Northwest Atlantic grey seal population 19772010. Can Sci Advis Sec Res Doc 2011/017

> Trites AW, Christensen V, Pauly D (1997) Competition between fisheries and marine mammals for prey and primary production in the Pacific Ocean. J Northwest Atl Fish Sci 22:173-187

Trzcinski MK, Mohn R, Bowen WD (2006) Continued decline of an Atlantic cod population: how important is gray seal predation? Ecol Appl 16:2276-2292

Trzcinski MK, Mohn R, Bowen WD (2009) Estimating the impact of grey seals on the eastern Scotian Shelf and western Scotian Shelf cod populations. Can Sci Advis Sec Res Doc 2009/052

Warren WG (1997) Report on the comparative fishing trial between the Gadus Atlantica and the Teleost. NAFO Sci Counc Stud 29:81-92

Warren WG, Brodie W, Stansbury DE, Walsh SJ, Morgan MJ, Orr D (1997) Analysis of the 1996 comparative fishing trial between the Alfred Needler with the Engel 145 trawl and the Wilfred Templeman with the Campelen 1800 trawl. NAFO Sci Counc Res Doc 97/68

- Wickens PA, Japp DW, Shelton PA, Kriel F and others (1992) Seals and fisheries in South Africa-competition and conflict. S Afr J Mar Sci 12:773-789

Yodzis P (1994) Predator-prey theory and management of multispecies fisheries. Ecol Appl 4:51-58

Yodzis P (1998) Local trophodynamics and the interaction of marine mammals and fisheries in the Benguela ecosystem. J Anim Ecol 67:635-658

Yodzis P, Innes S (1992) Body size and consumer-resource dynamics. Am Nat 139:1151-1175

Submitted: November 5, 2013; Accepted: May 30, 2014

Proofs received from author(s): September 9, 2014 